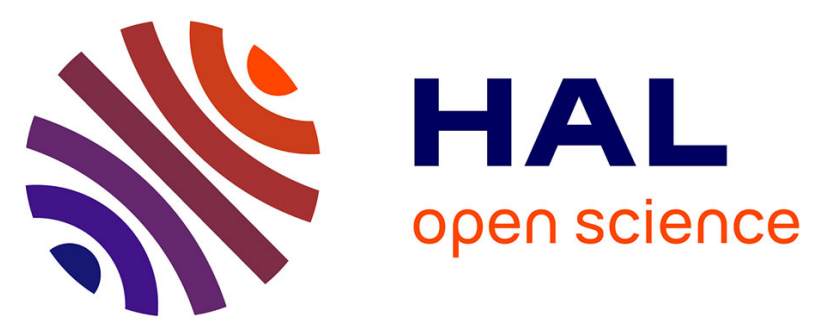

\title{
Unraveling the Direct Decomposition of NO x over Keggin Heteropolyacids and Their Deactivation Using a Combination of Gas-IR/MS and In Situ DRIFT Spectroscopy
}

Josefine Schnee, Laurent Delannoy, Guylène Costentin, Cyril Thomas

\section{To cite this version:}

Josefine Schnee, Laurent Delannoy, Guylène Costentin, Cyril Thomas. Unraveling the Direct Decomposition of $\mathrm{NO} \mathrm{x}$ over Keggin Heteropolyacids and Their Deactivation Using a Combination of Gas-IR/MS and In Situ DRIFT Spectroscopy. Journal of Physical Chemistry C, In press, 10.1021/acs.jpcc.0c05945 . hal-02960399

\section{HAL Id: hal-02960399 \\ https://hal.sorbonne-universite.fr/hal-02960399}

Submitted on 7 Oct 2020

HAL is a multi-disciplinary open access archive for the deposit and dissemination of scientific research documents, whether they are published or not. The documents may come from teaching and research institutions in France or abroad, or from public or private research centers.
L'archive ouverte pluridisciplinaire HAL, est destinée au dépôt et à la diffusion de documents scientifiques de niveau recherche, publiés ou non, émanant des établissements d'enseignement et de recherche français ou étrangers, des laboratoires publics ou privés. 


\title{
Unravelling the Direct Decomposition of $\mathrm{NO}_{x}$ over Keggin Heteropolyacids and their Deactivation Using a Combination of Gas-IR/MS and in Situ DRIFT
}

\author{
Josefine Schnee, * Laurent Delannoy, Guylène Costentin, and Cyril Thomas* \\ Sorbonne Université, CNRS, Laboratoire de Réactivité de Surface (LRS), F-75005 Paris, France. \\ *Corresponding authors: josefine.schnee@upmc.fr, josischnee@hotmail.com, cyril.thomas@upmc.fr.
}

\begin{abstract}
Keggin heteropolyacids (HPAs) have been known to be efficient $\mathrm{NO}_{x}$ absorbers for many years, and to decompose a significant fraction of the $\mathrm{NO}_{x}$ species pre-absorbed at $100-150{ }^{\circ} \mathrm{C}$ into harmless $\mathrm{N}_{2}$ and $\mathrm{O}_{2}$ upon rapid heating to $450{ }^{\circ} \mathrm{C}$. However, this capability of Keggin HPAs to directly decompose $\mathrm{NO}_{x}$ in the absence of reducing agent in the feed has never been studied under more realistic reaction conditions, e.g. under continuous $\mathrm{NO}_{x}$ feeding and in the presence of $\mathrm{O}_{2}$ in the feed. This was done for the first time in the present work, over the widely used $\mathrm{H}_{3} \mathrm{PW}_{12} \mathrm{O}_{40}$ Keggin HPA, at $380{ }^{\circ} \mathrm{C}$. $\mathrm{H}_{3} \mathrm{PW}_{12} \mathrm{O}_{40}$ was shown to be active in the direct decomposition of continuously fed $\mathrm{NO}_{x}$, with the decomposition process occurring through the involvement of $\mathrm{NOH}^{+}$adspecies. $\mathrm{O}_{2}$ was found to play a dual role. On the one hand, it led to the oxidation of $\mathrm{NO}$ into $\mathrm{NO}_{2}$ in the feed, with $\mathrm{NO}_{2}$ deactivating the HPA units. On the other hand, it was found to initiate the diffusion of $\mathrm{NO}_{x}$ into the bulk of the HPA crystals, which significantly enhanced the durability of the activity of the HPA in the direct decomposition of these $\mathrm{NO}_{x}$, provided that the diffusion pathway in-between the bulk Keggin units was already accessible thanks to the presence of $\mathrm{NO}_{x}$ species pre-absorbed at $\mathrm{RT}$. By providing the key factors involved in the direct decomposition of continuously fed $\mathrm{NO}_{x}$ over $\mathrm{H}_{3} \mathrm{PW}_{12} \mathrm{O}_{40}$, the present work paves the way for future investigations that might focus, for instance, on tuning the chemical composition of the heteropolyanions in order to make the HPA more resistant to deactivation.
\end{abstract}

\section{Introduction}

Heteropolyacids (HPAs) are metal-oxygen clusters which have a discrete ionic structure consisting of mobile elementary units, namely heteropolyanions and protons. This mobility is the source of very interesting catalytic properties. ${ }^{1,2}$ HPAs exhibit unique redox properties which can be tuned by varying their chemical composition. ${ }^{1,3}$ They also exhibit a very strong Brönsted acidity, being much stronger than that of conventional inorganic acids, and approaching the super-acid region. ${ }^{1,45}$ Among a large diversity of structures, Keggin HPAs are the most studied. Indeed, they are the most stable and the most easily available ones. ${ }^{2,6}$ The Keggin unit is composed of a heteropolyanion having the formula $\left[\mathrm{XM}_{12} \mathrm{O}_{40}\right]^{n_{-}}$(typically, $\mathrm{X}=\mathrm{P}$ or $\mathrm{Si}$ and $\mathrm{M}=\mathrm{W}$ or Mo) and being stabilized by $n$ acidic protons. ${ }^{6}$ The heteropolyanion is made of a central $\mathrm{XO}_{4}$ tetrahedron, surrounded by $12 \mathrm{MO}_{6}$ octahedra. ${ }^{7}$ It contains 3 types of oxygen atoms: central $\left(\mathrm{O}_{\mathrm{a}}\right)$, bridging, and terminal $\left(\mathrm{O}_{\mathrm{d}}\right)$ ones. The bridging ones are either corner-sharing $\left(\mathrm{O}_{\mathrm{b}}\right)$ or edge-sharing $\left(\mathrm{O}_{\mathrm{c}}\right)$. In the hydrated solid, Keggin units are coordinated with 
structural water molecules. Most commonly, six structural water molecules are contained per Keggin unit, forming a body-centered cubic structure with Keggin anions at the lattice points and acidic $\mathrm{H}_{5} \mathrm{O}_{2}{ }^{+}$ bridges along the faces. ${ }^{2,8}$

Keggin HPAs are known to be highly efficient absorbers of nitrogen oxides $\left(\mathrm{NO}_{x}\right)$ being among the major pollutants of the atmosphere. ${ }^{9} \mathrm{NO}_{x}$ largely contribute to current environmental issues such as photochemical smog, acid rain, tropospheric ozone, ozone layer depletion and global warming. ${ }^{10,11,12}$ At $100-150{ }^{\circ} \mathrm{C}$, the constitutive crystals of Keggin HPAs are reported to accommodate $\mathrm{NO}$ and $\mathrm{NO}_{2}$ within their bulk, thus in-between the $\left[\mathrm{XM}_{12} \mathrm{O}_{40}\right]^{n-}$ heteropolyanions, as $\mathrm{NOH}^{+}$and $\mathrm{HNO}_{2}{ }^{+}$moieties. ${ }^{9}$ Upon rapid heating $\left(150{ }^{\circ} \mathrm{C} / \mathrm{min}\right)$ to $450{ }^{\circ} \mathrm{C}$ under inert atmosphere, about $70 \%$ of the pre-absorbed $\mathrm{NO}_{x}$ species are decomposed into harmless $\mathrm{N}_{2}$ and $\mathrm{O}_{2} .{ }^{9}$ The term "absorption" refers here to the diffusion of $\mathrm{NO}_{x}$ into the bulk of the HPA crystals, in which $\mathrm{NO}_{x}$ adsorb as $\mathrm{NOH}^{+}$and $\mathrm{HNO}_{2}{ }^{+}$species onto the surface of the constitutive heteropolyanions. It does not refer to the diffusion of $\mathrm{NO}_{x}$ into the bulk of the Keggin units themselves. The mechanism of the $\mathrm{NO}_{x}$ decomposition process is still unclear. It is however generally accepted to involve the protons of the HPA. ${ }^{9}$

Although the capability of Keggin HPAs to directly decompose $\mathrm{NO}_{x}$ in the absence of reducing agent in the feed has been known for 25 years, it has, to our knowledge, never been studied under more realistic reaction conditions, e.g. under continuous $\mathrm{NO}_{x}$ feeding and in the presence of $\mathrm{O}_{2}$ in the feed. However, the catalytic direct $\mathrm{NO}_{x}$ decomposition is nowadays considered as offering an ideal solution to the abatement of $\mathrm{NO}_{x}$ from the exhausts of automotive and various combustion processes. ${ }^{10,12,13}$ The development of efficient formulations, classically based on noble metals, metal oxides or zeolites, is of the utmost interest to meet the ever more stringent emission regulations. ${ }^{10,11,12,14,15,16,17}$ As a reference, over Cu-ZSM- 5 being among the most active and stable catalysts reported for direct NO decomposition, NO decomposition rates of 0.134 and $8.16 \mu \mathrm{mol} / \mathrm{g}_{\text {catalyst }} / \mathrm{s}$ have been obtained with $\mathrm{Cu}(\mathrm{wt} \%)$ of 0.76 and 3.88 , respectively, in the absence of $\mathrm{O}_{2}$ in the feed (at $500{ }^{\circ} \mathrm{C}, 50 \mathrm{mg}$ catalyst, and a reaction feed consisting of $\mathrm{NO}(1 \%)$ in $\mathrm{He}(60 \mathrm{~mL} / \mathrm{min}$ total flow rate $)$, i.e. a WHSV of $\left.0.95 \mathrm{~g} / \mathrm{g}_{\text {catalyst }} / \mathrm{h}\right) .{ }^{15}$ Major efforts are currently focused on improving the tolerance of the catalysts to coexisting gases (e.g. $\mathrm{O}_{2}$, $\left.\mathrm{CO}_{2}, \mathrm{SO}_{2}\right) \cdot{ }^{11,13}$

In this context, the present work aims at investigating for the first time the potential of $\mathrm{H}_{3} \mathrm{PW}_{12} \mathrm{O}_{40}$, the most widely used Keggin HPA, in the direct decomposition of continuously fed $\mathrm{NO}_{x}$, at $380{ }^{\circ} \mathrm{C}$, namely the temperature above which the HPA starts to irreversibly lose its protons. ${ }^{18}$ An original methodology is proposed here to favor the $\mathrm{NO}_{x}$ decomposition process based on results recently reported in the literature for the HPAs system. On the one hand, NO was concluded to enter only the bulk of hydrated HPAs, and provided that $\mathrm{O}_{2}(1-5 \%)$ was contained in the feed. ${ }^{19,20}$ On the other hand, in the gas phase condensation of methanol into dimethylether (DME) at $150{ }^{\circ} \mathrm{C},{ }^{21,22}$ methanol was also found to be unable to enter the bulk of anhydrous HPA crystals at the reaction temperature, unless the HPA had been previously exposed to methanol at lower temperature (RT). This was ascribed to a strong enough surface pre-adsorption at RT, followed by diffusion into the bulk upon heating to $150{ }^{\circ} \mathrm{C}$ which 
finally further enabled the bulk of the HPA to become accessible also to methanol from the reaction feed at $150{ }^{\circ} \mathrm{C}$. This low-temperature methanol pre-exposure led to a 5 times higher methanol-to-DME conversion than observed over classically activated HPA. On this basis, in the present work, the $\mathrm{NO}_{x}$ decomposition reaction will be investigated without or with pre-exposure of the hydrated HPA sample to the $\mathrm{NO}-\mathrm{O}_{2}$ feed at RT. Through a combination of essentially gas-infrared analysis, mass spectrometry and in situ diffuse reflectance infrared Fourier-transform spectroscopy under various reaction conditions, the present work sheds light on the activity of $\mathrm{H}_{3} \mathrm{PW}_{12} \mathrm{O}_{40}$ in the aforementioned $\mathrm{NO}_{x}$ decomposition process, the nature of its active species in that process, and the sources of its deactivation. Thereby it unprecedentedly places HPAs into the category of materials to be considered on the way towards efficient formulations for direct $\mathrm{NO}_{x}$ decomposition.

\section{Experimental section}

\subsection{Sample preparation}

$\mathrm{H}_{3} \mathrm{PW}_{12} \mathrm{O}_{40}$ (hereafter HPW12) was purchased from Sigma-Aldrich in the form of $\mathrm{H}_{3} \mathrm{PW}_{12} \mathrm{O}_{40} . x \mathrm{H}_{2} \mathrm{O}$ (reagent grade). The powder was placed overnight under vacuum $(<5000 \mathrm{~Pa})$ at room temperature $(\mathrm{RT})$ in order to evacuate as much physisorbed water as possible. As revealed by a subsequent thermogravimetric analysis, the evacuated HPA contained 6 molecules of structural water per HPW12 unit ( $x=6$, thermogram not shown). Before experiments, the HPW12.6 $\mathrm{H}_{2} \mathrm{O}$ powder was sieved below $125 \mu \mathrm{m}$.

\subsection{Direct $N O_{x}$ decomposition experiments}

Direct $\mathrm{NO}_{x}$ decomposition experiments were carried out in a $\mathrm{U}$-shape quartz reactor ( $15 \mathrm{~mm}$ i.d.) at atmospheric pressure. The samples $(2.5 \mathrm{~g},<125 \mu \mathrm{m})$ were held on plugs of quartz wool, and the temperature was controlled by a temperature controller (Eurotherm 2408) using a K type thermocouple. The reaction feed consisted of $\mathrm{NO}(\sim 2000 \mathrm{ppm})$ in $\operatorname{Ar}(13 \%) / \mathrm{He}$, with or without $\mathrm{O}_{2}(5 \%$, if present), depending on the steps of the experiments (ppm and \% referring to volume). The constitutive gases were fed from independent gas cylinders (Air Liquide), through independent mass flow controllers (Brooks $5850 \mathrm{TR})$. The total flow rate was $50 \mathrm{~mL} \mathrm{NTP}_{\mathrm{N}} / \mathrm{min}$. The reactor inlet and outlet gas flows were analyzed with a gas-infrared (IR) analyzer (MKS MultiGas 2030), which allowed simultaneously detecting $\mathrm{H}_{2} \mathrm{O}$, $\mathrm{NO}, \mathrm{NO}_{2}$ and $\mathrm{N}_{2} \mathrm{O}$ (with 1 record every sec), as well as with a Pfeiffer Vacuum OmniStar mass spectrometer (MS) to qualitatively monitor the formation of $\mathrm{N}_{2}$ using $\mathrm{Ar}$ as an internal standard (with 1 record every 6-6.5 sec), and occasionally with an Agilent CP490 micro-gas chromatograph ( $\mu$-GC) to quantify $\mathrm{N}_{2}$ (with 1 injection every $3.5 \mathrm{~min}$ ). As the concentration of $\mathrm{N}_{2} \mathrm{O}$ remained below $0.6 \mathrm{ppm}$ in all experiments, it is not reported in the results and discussion section. 
In a first experiment, the sample - hereafter referred to as "N-HPW12" sample (N standing for non$\mathrm{NO}_{x}$-pre-saturated) - was heated from $\mathrm{RT}$ to $380^{\circ} \mathrm{C}$, the reaction temperature of interest in this work, at $10{ }^{\circ} \mathrm{C} / \mathrm{min}$ under $\mathrm{He}(50 \mathrm{~mL}$ NP $/ \mathrm{min})$. Once $\mathrm{H}_{2} \mathrm{O}$ was no longer detected by the gas-IR analyzer, i.e. once all of the structural water had been released (Figure S1a in the Supplementary Information), the sample was exposed to the $\mathrm{O}_{2}$-free reaction feed ( $2000 \mathrm{ppm} \mathrm{NO}-13 \% \mathrm{Ar} / \mathrm{He}$ ) for 60 minutes. Then, the sample was kept under static NO-Ar/He for 2 hours. Meanwhile, $\mathrm{O}_{2}$ was introduced into the NO$\mathrm{Ar} / \mathrm{He}$ feed. 2 hours was the time needed to achieve stable IR and MS traces. Finally, the sample was exposed overnight to the $\mathrm{O}_{2}$-containing reaction feed ( $2000 \mathrm{ppm} \mathrm{NO}-5 \% \mathrm{O}_{2}-13 \% \mathrm{Ar} / \mathrm{He}$ ).

In a second experiment, the sample was first pre-exposed to the $\mathrm{O}_{2}$-containing reaction feed at RT for 4.5 days until the $\mathrm{NO}_{x}\left(\mathrm{NO}+\mathrm{NO}_{2}\right)$ inlet readout was equivalent to the $\mathrm{NO}_{x}$ outlet readout. The resulting "P-HPW12" sample (P standing for $\mathrm{NO}_{x}$-pre-saturated) was then heated from $\mathrm{RT}$ to $380{ }^{\circ} \mathrm{C}$ at $3{ }^{\circ} \mathrm{C} / \mathrm{min}$ under $\operatorname{Ar}(8 \%) / \mathrm{He}(50 \mathrm{~mL} \mathrm{NTP} / \mathrm{min})$. The temperature ramp was slower than that used for $\mathrm{N}$ HPW12 to avoid decomposing the $\mathrm{NO}_{x}$ species, that might have been retained by the sample at RT, into $\mathrm{N}_{2}$ before reaching $380{ }^{\circ} \mathrm{C}^{23}$ At $380{ }^{\circ} \mathrm{C}$, once $\mathrm{H}_{2} \mathrm{O}$ was no longer detected by the gas-IR analyzer, i.e. once no structural water was released anymore (Figure S1b), the sample was first exposed overnight to the $\mathrm{O}_{2}$-free reaction feed ( $\left.2000 \mathrm{ppm} \mathrm{NO}-13 \% \mathrm{Ar} / \mathrm{He}\right)$, before being flushed under $\mathrm{He}(50 \mathrm{~mL} / \mathrm{NTP} / \mathrm{min})$ for 10 hours, and then being exposed once again to the same $\mathrm{O}_{2}$-free reaction feed for 3 hours. Finally, after having been kept under static NO-Ar/He for 2 hours (for the same reasons as N-HPW12 in the first experiment), the sample was exposed overnight to the $\mathrm{O}_{2}$-containing reaction feed ( $2000 \mathrm{ppm} \mathrm{NO}-$ $5 \% \mathrm{O}_{2}-13 \% \mathrm{Ar} / \mathrm{He}$ ). As explained in the introduction section, pre-exposing the hydrated HPW12 sample to the $\mathrm{O}_{2}$-containing $\mathrm{NO}$ feed at $\mathrm{RT}$ before dehydration (upon heating to $380{ }^{\circ} \mathrm{C}$ ) was likely to enable the protons located in the bulk of its crystals to participate in the direct decomposition of $\mathrm{NO}_{x}$ from the feed at $380{ }^{\circ} \mathrm{C}$.

The exposure of the samples to the $\mathrm{O}_{2}$-containing reaction feed at $380{ }^{\circ} \mathrm{C}$ in the above described experiments was repeated over fresh N-HPW12 and P-HPW12 samples (not having been beforehand exposed to the $\mathrm{O}_{2}$-free reaction feed at $380{ }^{\circ} \mathrm{C}$ ). As the results were essentially the same as those obtained in the above described experiments, they are not reported in the results and discussion section.

As references for these experiments, two blank experiments were also carried out, under the same reaction conditions as those aforementioned, but with only quartz wool in the reactor. The first reference experiment was performed with the $\mathrm{O}_{2}$-free reaction feed, whereas the second one was performed with the $\mathrm{O}_{2}(5 \%)$-containing feed.

\subsection{In situ diffuse reflectance Fourier-transform infrared (DRIFT) spectroscopy}

In order to gain further insight into the behavior of N-HPW12 and P-HPW12 under the $\mathrm{O}_{2}$-free and $\mathrm{O}_{2}(5 \%)$-containing reaction feeds, in situ diffuse reflectance infrared Fourier-transform (DRIFT) spectroscopy was carried out on similarly pre-treated samples under reaction conditions very close to those described in section 2.2, using a Bruker TENSOR II spectrometer. The reaction feed consisted of 
$\mathrm{NO}(\sim 2000 \mathrm{ppm})$ in $\operatorname{Ar}(40 \%) / \mathrm{He}\left(50 \mathrm{~mL} \mathrm{NTP} / \mathrm{min}\right.$ total flow rate), with or without $\mathrm{O}_{2}$ (5\%, if present), depending on the steps of the experiments. It was prepared using the gas distribution setup described in section 2.2, and then conducted through a Harrick heatable variable atmosphere cell (HVAC) equipped with two ZnSe windows and one quartz window, in which the sample holder was filled with powder of the HPW12 samples $(<125 \mu \mathrm{m})$. The content of Ar in the feed was higher than that used in the experiments described in section 2.2, for thermal conductivity reasons. The samples, referred to as $\mathrm{N}$ HPW12 and P-HPW12, were both heated from RT to $380{ }^{\circ} \mathrm{C}$ at $3{ }^{\circ} \mathrm{C} / \mathrm{min}$ under $\operatorname{Ar}(40 \%) / \mathrm{He}(50$ $\mathrm{mL}_{\mathrm{NTP}} / \mathrm{min}$ ). The pre-exposure of P-HPW12 to $\mathrm{NO}_{x}$ at RT was carried out in the IR cell, under the $\mathrm{O}_{2}$ containing reaction feed. At $380{ }^{\circ} \mathrm{C}$, the first exposure to $\mathrm{NO}_{x}$ was performed once the IR absorption band at $1740 \mathrm{~cm}^{-1}$, characteristic of the structural water within HPW12, ${ }^{19}$ had disappeared from the DRIFT spectrum (Figure S2, spectrum c vs. spectrum a of N-HPW12 at $380{ }^{\circ} \mathrm{C} v s$. RT, and spectrum d vs. spectrum b of P-HPW12 at $380{ }^{\circ} \mathrm{C} v s$. RT). ${ }^{19}$ In situ DRIFT spectra of the samples were recorded using 128 scans and a resolution of $4 \mathrm{~cm}^{-1}$. A reference spectrum was recorded with $\mathrm{KBr}$ (Fluka, purity $>99.5 \%)$ under the same operating $\left(\operatorname{Ar}(40 \%) / \mathrm{He}\left(50 \mathrm{~mL}_{\mathrm{NTP}} / \mathrm{min}\right)\right)$ and temperature conditions. The absolute spectra are reported in $\log 1 / \mathrm{R}$ with $\mathrm{R}=\mathrm{I}_{\text {sample }} / \mathrm{I}_{\mathrm{KBr}}$. The difference DRIFT spectra are reported in $\log 1 / R^{\prime}$ with the relative reflectance $R^{\prime}=I_{\text {sample }} / I_{\text {(reference sample) }} \cdot{ }^{24}$ Spectra processing was done using the Thermo Scientific OMNIC 9 software.

\section{Results and Discussion}

In the two blank experiments - one under the $\mathrm{O}_{2}$-free reaction feed, the other one under the $\mathrm{O}_{2}(5 \%)$ containing one - the MS-recorded mass to charge $(\mathrm{m} / \mathrm{z})$ ratio 28 associated with $\mathrm{N}_{2}$ normalized by the $\mathrm{m} / \mathrm{z} 40$ one associated with $\mathrm{Ar}$, as well as the sum of the $\mathrm{NO}$ and $\mathrm{NO}_{2}$ concentrations recorded by the gas-IR analyzer, remained essentially unchanged after flowing the reaction feed through the reactor at $380{ }^{\circ} \mathrm{C}$. This indicates that there was no $\mathrm{NO}_{x}$ decomposition to $\mathrm{N}_{2}$ occurring in the absence of HPW12 sample, and that there was no unwanted source of $\mathrm{N}_{2}$ formation associated with the reactor. As an example, the $\mathrm{N}_{2} / \mathrm{Ar}$ trace and the $\mathrm{NO}+\mathrm{NO}_{2}$ concentrations recorded in the presence of $\mathrm{O}_{2}$ in the feed are shown in Figure $\mathrm{S} 3$. Due to the presence of $\mathrm{O}_{2}$ in the feed, the $\mathrm{NO}$ and $\mathrm{NO}_{2}$ concentrations were impacted by the non-catalytic conversion of $\mathrm{NO}$ to $\mathrm{NO}_{2}$, to a larger extent after the feed had flown through the reactor at $380{ }^{\circ} \mathrm{C}$. This needs to be kept in mind for discussing the results obtained over the HPW12 samples in the following subsections.

\subsection{Activity of non- $\mathrm{NO}_{x}$-pre-saturated $\mathrm{H}_{3} \mathrm{PW}_{12} \mathrm{O}_{40}\left(\mathrm{~N}\right.$-HPW12) in the direct decomposition of $\mathrm{NO}_{x}$}

\subsubsection{In the absence of $\mathrm{O}_{2}$ in the reaction feed}

Figure 1 shows the $\mathrm{NO}$ and $\mathrm{NO}_{2}$ concentrations recorded by the gas-IR analyzer (panel a) as well as the MS-recorded mass to charge $(\mathrm{m} / \mathrm{z})$ ratios 28 and 32 associated with $\mathrm{N}_{2}$ and $\mathrm{O}_{2}$, respectively, 
normalized by the m/z 40 one associated with Ar (panels b and c, respectively) as a function of time on stream in the $\mathrm{NO}_{x}$ decomposition experiment carried out with the N-HPW12 sample at $380{ }^{\circ} \mathrm{C}$, in the absence of $\mathrm{O}_{2}$ in the reaction feed. The sample was previously heated from $\mathrm{RT}$ to $380{ }^{\circ} \mathrm{C}$ at $10{ }^{\circ} \mathrm{C} / \mathrm{min}$ under $\mathrm{He}\left(50 \mathrm{~mL} \mathrm{NTP}_{\mathrm{m}} / \mathrm{min}\right)$. The $\mathrm{NO}_{x}$ decomposition experiment was launched at $380{ }^{\circ} \mathrm{C}$ once no structural water was released from the sample anymore, as monitored with the gas-IR analyzer (Figure S1a). The reaction feed consisted of $\mathrm{NO}(\sim 2000 \mathrm{ppm})$ in $\operatorname{Ar}(13 \%) / \mathrm{He}\left(50 \mathrm{~mL}_{\mathrm{NTP}} / \mathrm{min}\right.$ total flow rate). In period (i) of Figure 1, the reaction feed was analyzed for $5 \mathrm{~min}$ (time -5 to $0 \mathrm{~min}$ ) without being contacted with the sample (upon flowing exclusively through lines at RT). In period (ii) of Figure 1, the reaction feed was continuously contacted with the sample at $380{ }^{\circ} \mathrm{C}$, and the outlet gas flow was analyzed over time on stream. 

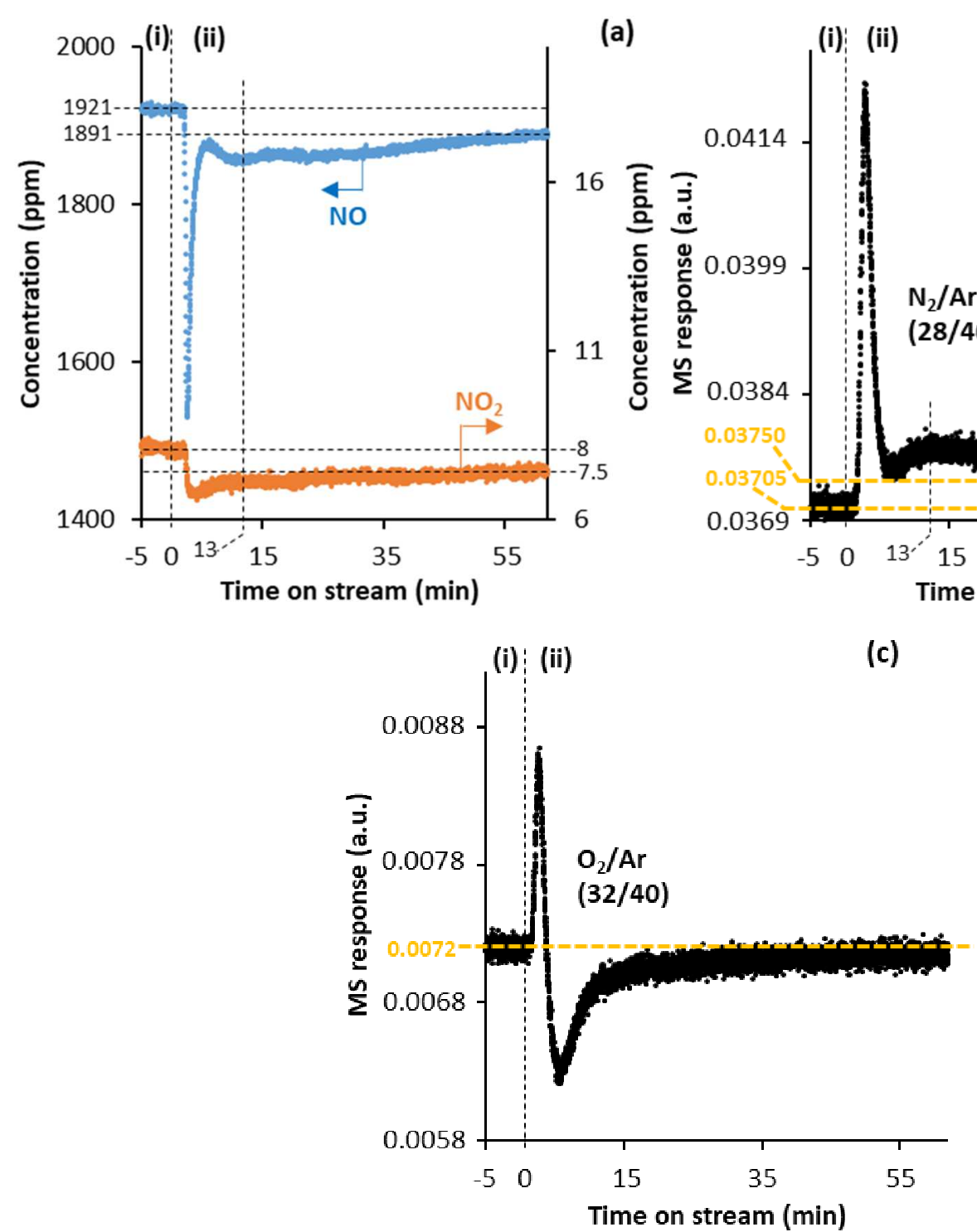

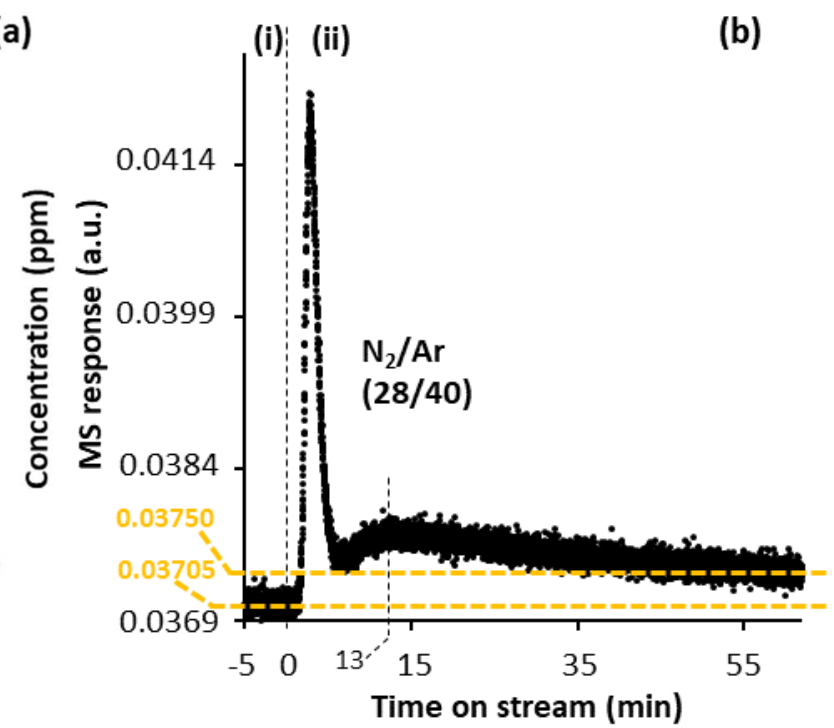

(c)

Figure 1. $\mathrm{NO}$ and $\mathrm{NO}_{2}$ concentrations recorded by the MKS MultiGas $2030 \mathrm{IR}$ analyzer (a) and mass to charge (m/z) ratios 28 and 32 associated with $\mathrm{N}_{2}$ and $\mathrm{O}_{2}$, respectively, normalized by the $\mathrm{m} / \mathrm{z} 40$ one associated with Ar recorded by the MS (b-c) as a function of time on stream in the $\mathrm{NO}_{x}$ decomposition experiment with $\mathrm{N}-\mathrm{HPW} 12(2.5 \mathrm{~g},<125 \mu \mathrm{m}, \mathrm{N}$ standing for non-NO pre-saturated) at $380{ }^{\circ} \mathrm{C}$ and a reaction feed consisting of $\mathrm{NO}(\sim 2000 \mathrm{ppm})$ in $\operatorname{Ar}(13 \%) / \mathrm{He}(50 \mathrm{~mL}$ TP/min). In (i), the reaction feed was analyzed without being contacted with the sample (upon flowing exclusively through lines at RT). In (ii), the reaction feed was continuously contacted with the sample at $380{ }^{\circ} \mathrm{C}$, and the outlet gas flow was analyzed over time on stream. NHPW 12 was previously heated from RT to $380{ }^{\circ} \mathrm{C}$ at $10{ }^{\circ} \mathrm{C} / \mathrm{min}$ under $\mathrm{He}(50 \mathrm{mLNTP} / \mathrm{min})$.

As measured by the gas-IR analyzer, the reaction feed contained $1921 \mathrm{ppm}$ of $\mathrm{NO}$ and $8 \mathrm{ppm}$ of $\mathrm{NO}_{2}$ (Figure 1a, period (i)). Upon starting period (ii) (time $=0 \mathrm{~min}$ ), the concentration of NO in the outlet gas flow (Figure 1a) dropped from 1921 to 1520 ppm within the first 2 min on stream, and then immediately increased until reaching $1874 \mathrm{ppm}$ at $6 \mathrm{~min}$ on stream. This initial peak of apparent NO consumption is attributed to the purge of the dead volume of the reactor, filled with He in period (i), upon introduction of the reaction feed. Afterwards, the recorded NO concentration evolved as a function of adsorption/reaction phenomena over the N-HPW12 sample. The concentration of NO first decreased from $1874 \mathrm{ppm}$ at $6 \mathrm{~min}$ on stream to $1859 \mathrm{ppm}$ at $13 \mathrm{~min}$ on stream. Then, it slowly increased until reaching $1891 \mathrm{ppm}$ at the end of period (ii). The concentration of $\mathrm{NO}_{2}$ remained between 6.5 and 7.5 
ppm over the whole period (ii). The fact that it was lower in period (ii) than in period (i) suggests that $\mathrm{NO}_{2}$ was partly adsorbed and/or converted on N-HPW12. The possible impact of the latter process on the interaction of N-HPW12 with NO will be discussed in the next sections (3.1.2, and 3.2 to 3.4).

The evolution of the $\mathrm{N}_{2} / \mathrm{Ar}$ trace recorded by the MS (Figure 1b) inversely follows that of the NO concentration (Figure 1a). In period (ii), following its initial peak attributed to the evacuation of traces of air from the dead volume of the reactor, the $\mathrm{N}_{2} / \mathrm{Ar}$ trace first increased from 5 to 13 min on stream, and then slowly decreased until the end of the experiment, reaching a final signal being however above that measured in period (i). According to a calibration based on $\mu-\mathrm{GC}$ measurements (the error associated to which is estimated to be about $1.6 \%$ ), the difference between the final $\mathrm{N}_{2} / \mathrm{Ar}$ signals in periods (ii) and (i) corresponds to about $18 \mathrm{ppm}$ of $\mathrm{N}_{2}$ produced, thus close to half the concentration of NO (30 ppm) missing in the outlet gas flow as compared to the feed (Figure 1a, end of period (ii) vs. period (i)). These results demonstrate, to our knowledge for the first time, that direct decomposition of $\mathrm{NO}$ into $\mathrm{N}_{2}\left(2 \mathrm{NO} \rightarrow \mathrm{N}_{2}+\mathrm{O}_{2}\right.$ ) occurs over HPW12 under continuous $\mathrm{NO}$ feeding at $380{ }^{\circ} \mathrm{C}$ (with a rate of $5.9 \times 10^{-16} \mu \mathrm{mol} / \mathrm{g}_{\mathrm{HPW} 12} / \mathrm{s}$ after $60 \mathrm{~min}$ on stream, with $2.5 \mathrm{~g}$ of HPW12 and a reaction feed consisting of $\mathrm{NO}(\sim 2000 \mathrm{ppm})$ in $\operatorname{Ar}(13 \%) / \mathrm{He}(50 \mathrm{~mL} \mathrm{NTP} / \mathrm{min})$, i.e. a WHSV of $\left.3.2 \times 10^{-3} \mathrm{~g} / \mathrm{g}_{\mathrm{HPW}} / \mathrm{h}\right)$. The evolution of this NO decomposition activity with time on stream is further discussed in section 3.4.

In period (ii) of Figure 1, the initial peak observed for the $\mathrm{N}_{2} / \mathrm{Ar}$ trace (Figure 1b), which was attributed earlier to the evacuation of traces of air from the dead volume of the reactor, was also observed for the $\mathrm{O}_{2} /$ Ar trace (Figure 1c). Afterwards, however, while the $\mathrm{N}_{2} /$ Ar trace increased from 5 to 13 min on stream, and then slowly decreased until the end of the experiment, reaching a final signal being however above that measured in period (i) (Figure 1b), the $\mathrm{O}_{2} / \mathrm{Ar}$ trace first decreased until 8 min on stream, and then increased until the end of the experiment (rapidly from 8 to 15 min on stream, then more slowly from 15 min on stream to the end), reaching a final signal being slightly below that measured in period (i) (Figure 1c). This comparison suggests that, while $\mathrm{N}_{2}$ was produced over N-HPW12 by NO decomposition, traces of $\mathrm{O}_{2}$ contained in the $\mathrm{NO}$ feed and/or $\mathrm{O}_{2}$ produced together with $\mathrm{N}_{2}$ over $\mathrm{N}$ HPW 12 by NO decomposition were getting adsorbed/not getting desorbed onto/from the Keggin units. The link between the latter phenomenon and the decreasing activity of N-HPW12 in Figure 1a-b will be made in section 3.4.2. Non-catalytic $\mathrm{NO}$ oxidation into $\mathrm{NO}_{2}$ with traces of $\mathrm{O}_{2}$ contained in the $\mathrm{NO}$ feed or $\mathrm{O}_{2}$ produced from the NO decomposition process over N-HPW12 must be negligible, as the concentration of NO converted ( $30 \mathrm{ppm}$ at the end of the experiment, Figure 1a) was close to that expected from the concentration of $\mathrm{N}_{2}$ produced (18 ppm at the end of the experiment, Figure $1 \mathrm{~b}$ ).

\subsubsection{In the presence of $\mathrm{O}_{2}$ in the reaction feed}

Figure 2 shows the $\mathrm{NO}$ and $\mathrm{NO}_{2}$ concentrations recorded by the gas-IR analyzer in the $\mathrm{NO}_{x}$ decomposition experiment over N-HPW12 at $380{ }^{\circ} \mathrm{C}$ in the presence of $\mathrm{O}_{2}$ in the reaction feed (with panels a and $b$ showing the same data over two different time scales, for the sake of clarity). In period 
(i), the reaction feed consisting of $\mathrm{NO}(\sim 2000 \mathrm{ppm})$ in $\mathrm{O}_{2}(5 \%)-\operatorname{Ar}(13 \%) / \mathrm{He}(50 \mathrm{~mL} / \mathrm{NT} / \mathrm{min})$ was analyzed for 5 min without being contacted with the sample (upon flowing exclusively through lines at RT). It was found to contain $1770 \mathrm{ppm}$ of $\mathrm{NO}$ and $194 \mathrm{ppm}$ of $\mathrm{NO}_{2}$ (Figure 2a). Meanwhile, the sample was kept under static $\mathrm{NO}-\mathrm{Ar} / \mathrm{He}$ (from the $\mathrm{O}_{2}$-free reaction feed used in the preceding step of the experiment, Figure 1). In period (ii), the reaction feed was continuously contacted with the sample at $380^{\circ} \mathrm{C}$, and the outlet gas flow was analyzed over time on stream.
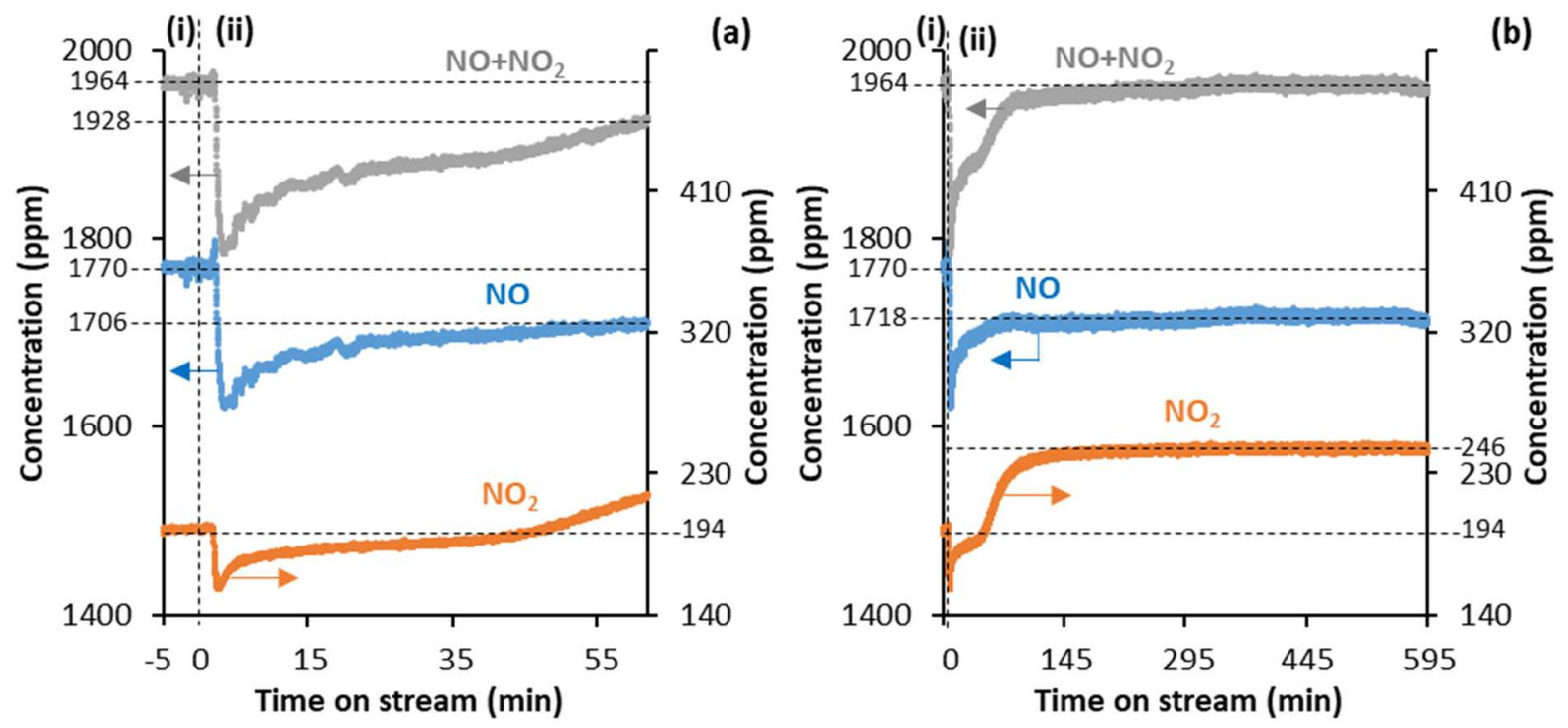

Figure 2. $\mathrm{NO}$ and $\mathrm{NO}_{2}$ concentrations recorded by the MKS MultiGas $2030 \mathrm{IR}$ analyzer as a function of time on stream in the $\mathrm{NO}_{x}$ decomposition experiment with N-HPW12 $(2.5 \mathrm{~g},<125 \mu \mathrm{m}, \mathrm{N}$ standing for non-NO $x$-pre-saturated $)$ at $380{ }^{\circ} \mathrm{C}$ and a reaction feed consisting of $\mathrm{NO}(\sim 2000 \mathrm{ppm})$ in $\mathrm{O}_{2}(5 \%)-\mathrm{Ar}(13 \%) / \mathrm{He}(50 \mathrm{mLNTP} / \mathrm{min})$. In (b), for the sake of clarity, the same data as in (a) is shown over a longer time scale. In (i), the reaction feed was analyzed without being contacted with the sample (upon flowing exclusively through lines at RT). In (ii), the reaction feed was continuously contacted with the sample at 380 ${ }^{\circ} \mathrm{C}$, and the outlet gas flow was analyzed over time on stream. N-HPW12 was previously heated from RT to $380{ }^{\circ} \mathrm{C}$ at 10 ${ }^{\circ} \mathrm{C} / \mathrm{min}$ under $\mathrm{He}(50 \mathrm{~mL} \mathrm{NTP} / \mathrm{min})$.

The total $\mathrm{NO}_{x}$ concentration in the outlet gas flow in period (ii) remained lower than that in the feed in period (i) for about $300 \mathrm{~min}$ on stream. Given that $\mathrm{N}_{2} / \mathrm{Ar}$ trace remained essentially unchanged after contacting the reaction feed with the sample (not shown), as also reported for the blank experiment over quartz wool (Figure $\mathrm{S} 3 \mathrm{~b}-\mathrm{c}$ ), $\mathrm{NO}_{x}$ species did not decompose into $\mathrm{N}_{2}$, but were retained by the N-HPW12 sample in these first $300 \mathrm{~min}$ on stream (Figure 2). The $\mathrm{NO}_{x}$ species retained by the sample consisted mostly of $\mathrm{NO}_{2}$, as indicated by the comparison of the concentrations of $\mathrm{NO}$ and $\mathrm{NO}_{2}$ in the first 300 min on stream with those after 300 min on stream (Figure $2 b$ ), once the total $\mathrm{NO}_{x}$ concentration had finally reached the same level as in the feed (no $\mathrm{NO}_{x}$ species were retained anymore by the N-HPW12 sample). In the latter period, after $300 \mathrm{~min}$ on stream, the final $\mathrm{NO} /\left(\mathrm{NO}+\mathrm{NO}_{2}\right)$ and $\mathrm{NO}_{2} /\left(\mathrm{NO}+\mathrm{NO}_{2}\right)$ concentration ratios $(1718 / 1964=0.875$ and $246 / 1964=0.125$, respectively, as measured in several repeat experiments) were slightly higher and lower, respectively, than the reference ratios observed over quartz wool at $380{ }^{\circ} \mathrm{C}(1675 / 1947=0.86$ and $272 / 1947=0.14$, respectively, Figure S3a $)$, with the reference ratios being dictated by the non-catalytic oxidation of $\mathrm{NO}$ to $\mathrm{NO}_{2}$. This suggests that N-HPW12 catalyzed the conversion of some $\mathrm{NO}_{2}$ back to $\mathrm{NO}$ (whereas at RT, N-HPW12 was found to catalyze 
the oxidation of NO, Figure 3). Indeed, at $380{ }^{\circ} \mathrm{C}$, even if their Keggin structure is maintained, ${ }^{18}$ the heteropolyanions may be deficient in structural oxygen atoms, and therefore may act as reducing agents towards $\mathrm{NO}_{2}$. Actually, the filling of their $\mathrm{O}$ vacancies along with the reduction of $\mathrm{NO}_{2}$ might explain the inactivity of N-HPW12 in the direct decomposition of $\mathrm{NO}_{x}$ in the present experiment, whereas this sample was found to be active in this reaction in the absence of $\mathrm{O}_{2}$ in the feed (Figure 1). In collaboration with the protons known to activate $\mathrm{NO}$ and $\mathrm{NO}_{2}$ to form $\mathrm{NOH}^{+}$and $\mathrm{HNO}_{2}{ }^{+}$species, respectively, ${ }^{9,23}$ the lacunary heteropolyanions might be the reductants required to finally decompose $\mathrm{NO}$ into $\mathrm{N}_{2}$. A direct filling of the $\mathrm{O}$ vacancies by $\mathrm{O}_{2}$ might then also contribute to the deactivation of N-HPW12, together with a possible poisoning of the protons by $\mathrm{NO}_{2}$ to form stable $\mathrm{HNO}_{2}{ }^{+}$species preventing $\mathrm{NO}$ from being activated. The deactivation of N-HPW12 after exposure to the $\mathrm{O}_{2}$-containing reaction feed at 380 ${ }^{\circ} \mathrm{C}$ was found to be irreversible as no $\mathrm{NO}_{x}$ decomposition could be recorded when removing $\mathrm{O}_{2}$ from the reaction feed (not shown).

\subsection{Pre-saturation of $\mathrm{H}_{3} \mathrm{PW}_{12} \mathrm{O}_{40}$ (HPW12) with $\mathrm{NO}_{x}$ species to yield the P-HPW12 sample}

In the second $\mathrm{NO}_{x}$ decomposition experiment performed in the present work, $\mathrm{HPW} 12.6 \mathrm{H}_{2} \mathrm{O}$ was first exposed to $\mathrm{NO}(\sim 2000 \mathrm{ppm})$ in $\mathrm{O}_{2}(5 \%)-\operatorname{Ar}(13 \%) / \mathrm{He}\left(50 \mathrm{~mL} \mathrm{NTP}_{\mathrm{N}} / \mathrm{min}\right)$ at $\mathrm{RT}$ before being heated under $\operatorname{Ar}(8 \%) / \mathrm{He}\left(50 \mathrm{~mL} \mathrm{NTP}_{\mathrm{N}} / \mathrm{min}\right)$ to the reaction temperature $380{ }^{\circ} \mathrm{C}\left(3{ }^{\circ} \mathrm{C} / \mathrm{min}\right)$. The sample obtained at the end of the pre-exposure step at RT is labelled as "P-HPW12" (P standing for $\mathrm{NO}_{x}$-pre-saturated). The $\mathrm{NO}$ and $\mathrm{NO}_{2}$ concentrations recorded by the gas-IR analyzer during the $\mathrm{NO}_{x}$-pre-exposure step are shown in Figure 3 (with panels a and b showing the same data over two different time scales, for the sake of clarity). In period (i), the NO- $\mathrm{O}_{2}$ feed was analyzed without being contacted with the sample. It was found to contain $1732 \mathrm{ppm}$ of $\mathrm{NO}$ and $177 \mathrm{ppm}$ of $\mathrm{NO}_{2}$ (Figure 3a), due to the non-catalytic conversion of $\mathrm{NO}$ to $\mathrm{NO}_{2}$ in the stainless-steel feeding lines. In period (ii), the feed was contacted with the sample, and the outlet gas flow was analyzed over time on stream. 

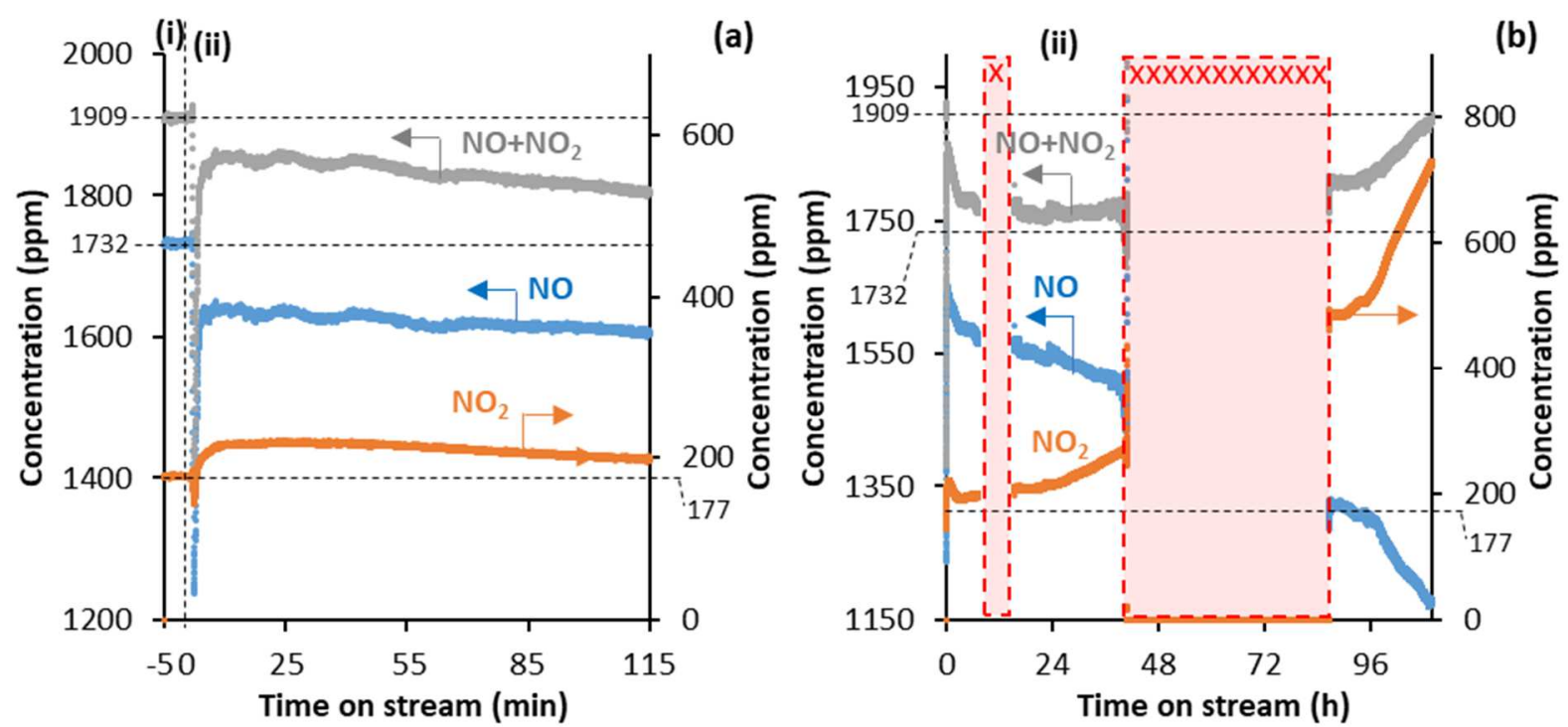

Figure 3. $\mathrm{NO}$ and $\mathrm{NO}_{2}$ concentrations recorded by the MKS MultiGas $2030 \mathrm{IR}$ analyzer as a function of time on stream in the pre-exposure of HPW12 $(2.5 \mathrm{~g},<125 \mu \mathrm{m})$ to a $50 \mathrm{mLNTP} / \mathrm{min}$ feed of $\mathrm{NO}(\sim 2000 \mathrm{ppm})$ in $\mathrm{O}_{2}(5 \%)-\operatorname{Ar}(13 \%) / \mathrm{He}$ at RT, to yield the P-HPW12 sample. In (i), the feed was analyzed without being contacted with the sample. In (ii), the feed was contacted with the sample, and the outlet gas flow was analyzed over time on stream. (b) shows the same traces as (a), but over a longer time scale. The periods marked with crosses (xxx) correspond to night and/or weekend periods in which the cryo-detector of the IR analyzer could not be filled with liquid $\mathrm{N}_{2}$.

The sum of the $\mathrm{NO}$ and $\mathrm{NO}_{2}$ concentrations remained below its initial level of period (i) for 4.5 days on stream (Figure 3b). The missing $\mathrm{NO}_{x}\left(\mathrm{NO}+\mathrm{NO}_{2}\right)$ concentration in the outlet gas flow was integrated over the whole 4.5 days on stream, by roughly interpolating the $\mathrm{NO}_{x}$ concentration in the periods of missing data (i.e. night and weekend periods during which the cryo-detector of the analyzer could not be filled with liquid $\mathrm{N}_{2}$ ). This yielded a value of $0.0020 \mathrm{~mol}$ of $\mathrm{NO}_{x}$ retained by the sample, that corresponds to $81 \%$ of the total amount of protons $(0.0024 \mathrm{~mol})$ contained in the sample $(2.5 \mathrm{~g})$. Given that surface protons represent only $4 \%$ of the total number of protons of HPW $12,{ }^{22}$ the amount of $\mathrm{NO}_{x}$ stored in the present experiment as $\mathrm{NOH}^{+}$or $\mathrm{HNO}_{2}{ }^{+}$species ${ }^{19,20}$ ( $81 \%$ of the protons) demonstrates that $\mathrm{NO}_{x}$ had largely entered the bulk of the P-HPW12 crystals, which confirms the great potential of Keggin HPAs as $\mathrm{NO}_{x}$ absorber materials, as pointed out in the introduction section. ${ }^{9}$ Thereby, the structural water was progressively evacuated from the P-HPW12 crystals during the pre-exposure to $\mathrm{NO}_{x}$ at $\mathrm{RT}$ (Figure S4). This explains why, upon heating the P-HPW12 sample afterwards from RT to $380{ }^{\circ} \mathrm{C}$ (3 ${ }^{\circ} \mathrm{C} / \mathrm{min}$ ) under $\operatorname{Ar}(8 \%) / \mathrm{He}\left(50 \mathrm{~mL}_{\mathrm{NTP}} / \mathrm{min}\right)$, only $25 \%$ of the total amount of structural water theoretically contained in $\mathrm{HPW} 12.6 \mathrm{H}_{2} \mathrm{O}(2.5 \mathrm{~g})$ was released (Figure $\left.\mathrm{S} 1 \mathrm{~b}\right)$. It can therefore be concluded that the pre-exposure of the HPW12 sample to $\mathrm{NO}_{x}$ at RT had already evacuated $75 \%$ of the structural water.

At the very end of period (ii), when the total $\mathrm{NO}_{x}$ concentration in the outlet gas flow was equal to that in the feed (1909 ppm in period (i)), indicating that $\mathrm{NO}_{x}$ absorption by P-HPW12 was completed, the concentrations of $\mathrm{NO}$ and $\mathrm{NO}_{2}$ were significantly lower and higher, respectively, than those in the feed (1174 vs. $1732 \mathrm{ppm}$ and 736 vs. $177 \mathrm{ppm}$, respectively). This is attributed to the catalytic oxidation of $\mathrm{NO}$ into $\mathrm{NO}_{2}$ at the surface of P-HPW12. ${ }^{19}$ The total amounts of $\mathrm{NO}$ and $\mathrm{NO}_{2}$ retained by the sample 
can be assumed to be similar, as upon heating the P-HPW12 sample afterwards from RT to $380{ }^{\circ} \mathrm{C}$ ( 3 $\left.{ }^{\circ} \mathrm{C} / \mathrm{min}\right)$ under $\operatorname{Ar}(8 \%) / \mathrm{He}\left(50 \mathrm{~mL}\right.$ NTP/min), nearly the same amounts of $\mathrm{NO}$ and $\mathrm{NO}_{2}$ were released $(7.42$ $\mathrm{x} 10^{-5} \mathrm{~mol}$ of $\mathrm{NO}$ vs. $7.61 \times 10^{-5} \mathrm{~mol}$ of $\mathrm{NO}_{2}$, Figure S5a). Notice that the total amount of $\mathrm{NO}_{x}$ released ( $1.503 \times 10^{-4} \mathrm{~mol}$ ) upon heating the P-HPW12 sample from RT to $380{ }^{\circ} \mathrm{C}$ corresponds to only $7.5 \%$ of the 0.0020 mol of $\mathrm{NO}_{x}$ initially retained at RT. Some $\mathrm{N}_{2}$ was also detected upon heating the P-HPW12 sample from RT to $380{ }^{\circ} \mathrm{C}$ (Figure S5b), but as the temperature ramp used was as slow as $3{ }^{\circ} \mathrm{C} / \mathrm{min}$, according to earlier literature reports, the corresponding $\mathrm{N}_{2}$ amount remained limited to about $5 \%$ of the pre-absorbed $\mathrm{NO}_{x}$ species. ${ }^{9,23}$ Once the temperature was stabilized at $380{ }^{\circ} \mathrm{C}$, no $\mathrm{N}_{2}$ was formed anymore, showing that the pre-absorbed $\mathrm{NO}_{x}$ species were unable to decompose at a constant temperature of $380{ }^{\circ} \mathrm{C}$ under inert atmosphere. Overall, it can be concluded that the sample still contained the majority of its pre-absorbed $\mathrm{NO}_{x}$ species at the start of the experiment performed with continuously fed $\mathrm{NO}_{x}$ at $380{ }^{\circ} \mathrm{C}$.

\subsection{Activity of $\mathrm{NO}_{x}$-pre-saturated $\mathrm{H}_{3} \mathrm{PW}_{12} \mathrm{O}_{40}(\mathrm{P}-\mathrm{HPW12})$ in the direct decomposition of $\mathrm{NO}_{x}$}

3.3.1. In the absence of $\mathrm{O}_{2}$ in the reaction feed-Elucidating the deactivating impact of $\mathrm{NO}_{2}$ on the activity of HPW12

Figure 4a shows the $\mathrm{NO}$ and $\mathrm{NO}_{2}$ concentrations recorded by the gas-IR analyzer as a function of time on stream in the $\mathrm{NO}_{x}$ decomposition experiment over the P-HPW12 sample at $380{ }^{\circ} \mathrm{C}$, in the absence of $\mathrm{O}_{2}$ in the reaction feed. In period (i), the reaction feed - NO ( $\left.2000 \mathrm{ppm}\right)$ in $\mathrm{Ar}(13 \%) / \mathrm{He}-$ was analyzed for $5 \mathrm{~min}$ without being contacted with the sample (upon flowing exclusively through lines at RT). It was found to contain 1919 ppm of $\mathrm{NO}$ and $7 \mathrm{ppm}$ of $\mathrm{NO}_{2}$. Meanwhile, the sample was kept under static $\mathrm{Ar} / \mathrm{He}$, the atmosphere under which the sample was previously heated from RT to 380 ${ }^{\circ} \mathrm{C}$. In period (ii), the reaction feed was continuously contacted with the sample at $380{ }^{\circ} \mathrm{C}$, and the outlet gas flow was analyzed over time on stream. Figure S6 shows the same concentrations over a longer time scale (600 min). 


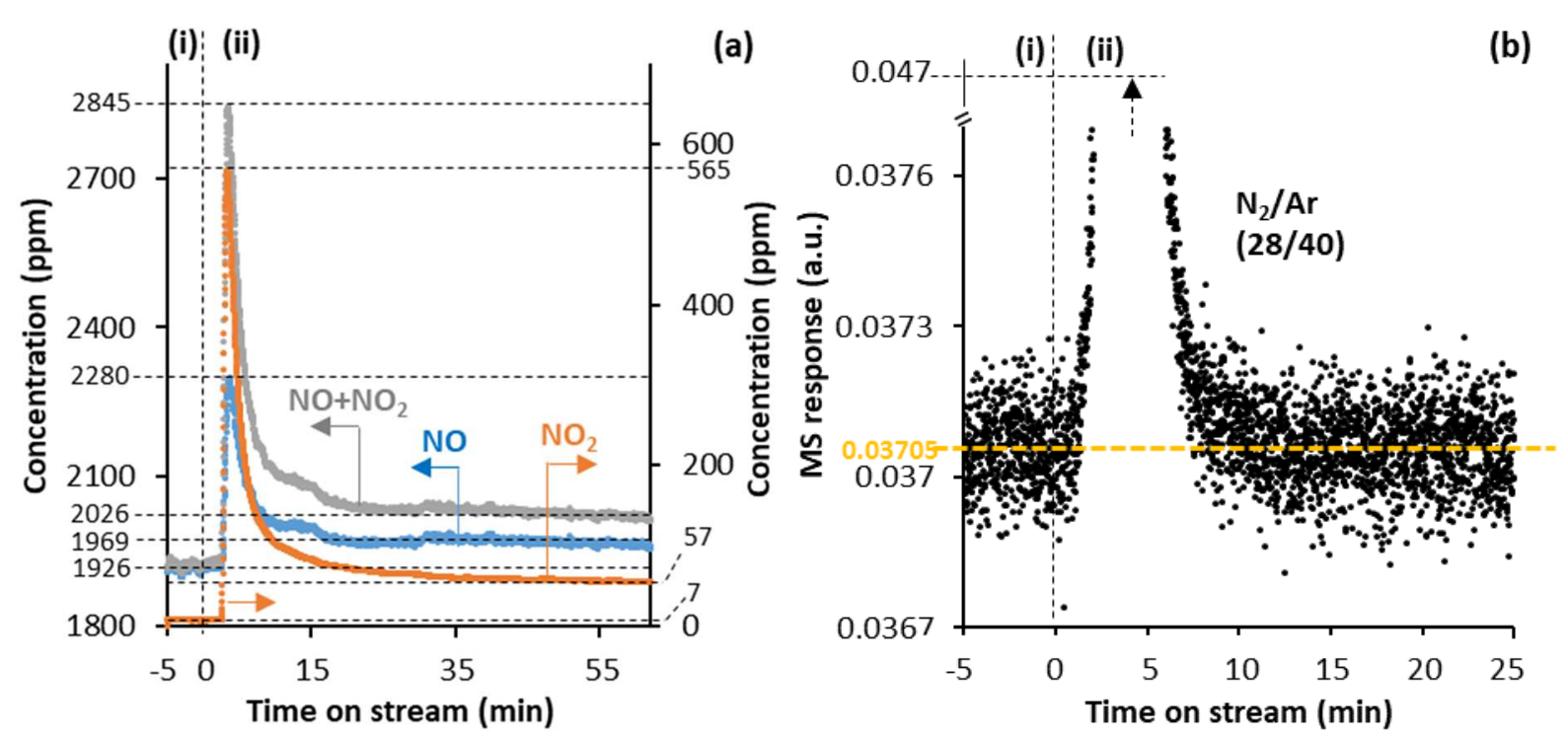

Figure 4. $\mathrm{NO}$ and $\mathrm{NO}_{2}$ concentrations recorded by the MKS MultiGas 2030 IR analyzer (a) and mass to charge (m/z) ratio 28 associated with $\mathrm{N}_{2}$ normalized by the $\mathrm{m} / \mathrm{z} 40$ one associated with Ar recorded by the MS (b) vs. time on stream in the $\mathrm{NO}_{x}$ decomposition experiment with P-HPW12 $\left(2.5 \mathrm{~g},<125 \mu \mathrm{m}, \mathrm{P}\right.$ standing for $\mathrm{NO}_{x}$-pre-saturated $)$ at $380{ }^{\circ} \mathrm{C}$ and a reaction feed consisting of $\mathrm{NO}(\sim 2000 \mathrm{ppm})$ in $\mathrm{Ar}(13 \%) / \mathrm{He}(50 \mathrm{~mL}$ TP $/ \mathrm{min})$. In (i), the reaction feed was analyzed without being contacted with the sample (upon flowing exclusively through lines at RT). In (ii), the reaction feed was continuously contacted with the sample at $380^{\circ} \mathrm{C}$, and the outlet gas flow was analyzed over time on stream. The $\mathrm{N}_{2} / \mathrm{Ar}$ peak at around 5 min on stream has no analytical interest here. It is attributed to the release of air trapped in the valve that served for contacting the reaction feed with the sample. Its upper intensity was cut from the graph, as indicated by the rising arrow. The P-HPW12 sample was previously heated from RT to $380{ }^{\circ} \mathrm{C}$ at $3{ }^{\circ} \mathrm{C} / \mathrm{min}$ under $\operatorname{Ar}(8 \%) / \mathrm{He}(50 \mathrm{mLNTP} / \mathrm{min})$.

Within the first 3 min of period (ii), the concentrations of $\mathrm{NO}$ and $\mathrm{NO}_{2}$ in the outlet gas flow rose up quickly to 2280 and $565 \mathrm{ppm}$, respectively, whereas they were found to drop in the equivalent experiment over N-HPW12 (Figure 1). This indicates that, during the preceding period (i), the static $\mathrm{Ar} / \mathrm{He}$ atmosphere had been progressively enriched in $\mathrm{NO}$ and $\mathrm{NO}_{2}$ being released from the sample, until it was evacuated along with the introduction of the reaction feed. Then, following this initial $\mathrm{NO}_{x}$ peak in period (ii), both the $\mathrm{NO}$ and $\mathrm{NO}_{2}$ concentrations decreased until reaching, at about 35 min on stream, stable levels of 1969 and $57 \mathrm{ppm}$, respectively. These concentrations were both $50 \mathrm{ppm}$ higher than those in the feed recorded in period (i), indicating that the sample was continuously releasing 50 ppm of both $\mathrm{NO}$ and $\mathrm{NO}_{2}$, namely 4.4 times less $\mathrm{NO}$ and $\mathrm{NO}_{2}$ than released under $\operatorname{Ar}(8 \%) / \mathrm{He}$ right before switching to period (i) (Figure S5a, $219 \mathrm{ppm}$ of both $\mathrm{NO}$ and $\mathrm{NO}_{2}$ released at $184 \mathrm{~min}$ on stream). Thus, under reaction conditions, the NO feed essentially prevented the sample from releasing its preabsorbed $\mathrm{NO}_{x}$ species. However, unlike in the experiment carried out over N-HPW12 in the absence of $\mathrm{O}_{2}$ in the feed (Figure 1), $\mathrm{NO}$ from the feed was not decomposed to $\mathrm{N}_{2}$, as the $\mathrm{N}_{2} / \mathrm{Ar}$ MS trace remained essentially unchanged from period (i) to period (ii) (Figure $4 \mathrm{~b}$ ). The absence of $\mathrm{NO}_{x}$ decomposition activity of P-HPW12, whereas N-HPW12 was active under the same $\mathrm{O}_{2}$-free conditions, can only be attributed to the presence and/or the release of $\mathrm{NO}_{2}$ in the/out of the bulk of its crystals, which is the only significant difference between the experiments carried out on these two samples in the absence of $\mathrm{O}_{2}$ in the feed. As in the experiment performed over N-HPW12 in the presence of $\mathrm{O}_{2}$ in the feed, $\mathrm{NO}_{2}$ might have filled the $\mathrm{O}$ vacancies of the heteropolyanions, preventing them from playing their possible 
role as NO reductants, or might have poisoned the protons to form unreactive $\mathrm{HNO}_{2}{ }^{+}$species, eventually preventing NO from being activated.

Following this first $\mathrm{NO}_{x}$ decomposition experiment over P-HPW12 at $380{ }^{\circ} \mathrm{C}$ in the absence of $\mathrm{O}_{2}$ in the feed (Figure 4), the sample was purged under $\mathrm{He}(50 \mathrm{~mL} \mathrm{NTP} / \mathrm{min})$ at $380{ }^{\circ} \mathrm{C}$ for 10 hours, before being exposed a second time to the same $\mathrm{O}_{2}$-free reaction feed for 3 hours (Figure S7). During this second exposure to the $\mathrm{O}_{2}$-free reaction feed, the concentrations of $\mathrm{NO}$ and $\mathrm{NO}_{2}$ continuously released from the sample were lower than in the first reaction step (Figure S7 vs. Figure 4). From about 50 min on stream, once the concentrations had stabilized, only $20 \mathrm{ppm}$ of both $\mathrm{NO}$ and $\mathrm{NO}_{2}$ were released (whereas 50 ppm were released in the first experiment, Figure 4). This shows that the amount of $\mathrm{NO}_{x}$ species released in the feed in the course of the experiment depends on the amount of $\mathrm{NO}_{x}$ species stored in the sample, the latter amount being lower after the purge step during which a part of the pre-absorbed $\mathrm{NO}_{x}$ species was released (not shown). As in the first experiment, the $\mathrm{NO}_{x}$ (fed and pre-absorbed) were not found to decompose into $\mathrm{N}_{2}$ (not shown).

3.3.2. In the presence of $\mathrm{O}_{2}$ in the reaction feed-Elucidating the positive impact of $\mathrm{O}_{2}$ on the activity of $H P W 12$

The P-HPW12 sample already used in the two latter experiments (section 3.3.1) was finally submitted to a $\mathrm{NO}_{x}$ decomposition experiment at $380{ }^{\circ} \mathrm{C}$ in the presence of $\mathrm{O}_{2}$ in the reaction feed. The $\mathrm{NO}$ and $\mathrm{NO}_{2}$ concentrations recorded by the gas-IR analyzer as a function of time on stream are shown in Figure 5a-b (with panels a and b showing the same data over two different time scales, for the sake of clarity), whereas the $\mathrm{N}_{2} / \mathrm{Ar}$ trace recorded by the MS is shown in Figure 5c. In period (i), the reaction feed consisting of $\mathrm{NO}(\sim 2000 \mathrm{ppm})$ in $\mathrm{O}_{2}(5 \%)-\mathrm{Ar}(13 \%) / \mathrm{He}\left(50 \mathrm{~mL} \mathrm{NTP}_{\mathrm{N}} / \mathrm{min}\right)$ was analyzed for $5 \mathrm{~min}$ without being contacted with the sample (upon flowing exclusively through lines at RT). It was found to contain $1736 \mathrm{ppm}$ of $\mathrm{NO}$ and $181 \mathrm{ppm}$ of $\mathrm{NO}_{2}$. Meanwhile, the sample was kept under static NO$\mathrm{Ar} / \mathrm{He}$ (from the $\mathrm{O}_{2}$-free reaction feed used in the preceding step of the experiment, Figure 4). In period (ii), the reaction feed was continuously contacted with the sample at $380^{\circ} \mathrm{C}$, and the outlet gas flow was analyzed over time on stream.

In period (ii) of Figure 5a-b, the total $\mathrm{NO}_{x}$ concentration in the outlet gas flow first decreased, and then immediately increased to slightly above its level in the feed. Then, it decreased again up to about $20 \mathrm{~min}$ on stream, before remaining below its level in the feed until the end of the experiment. Thus, unlike in the absence of $\mathrm{O}_{2}$ in the feed (Figure 4a), $\mathrm{NO}_{x}$ from the feed were retained by the P-HPW12 sample in the presence of $\mathrm{O}_{2}$ in the feed. The fact that the $\mathrm{NO}, \mathrm{NO}_{2}$ and total $\mathrm{NO}_{x}$ concentrations remained essentially constant from about 20 to 100 min on stream (Figure 5a-b) indicates that $\mathrm{NO}_{x}$ were retained not only at the surface but also in the bulk of P-HPW12. Indeed, in the pre-saturation of P-HPW12 with $\mathrm{NO}_{x}$ at RT, the $\mathrm{NO}_{x}$ concentration was also constant for a significant period of time (Figure $3 \mathrm{~b}$ ), and this was demonstrated in section 3.2 to arise from bulk absorption, probably due to diffusion limitations inbetween the constitutive HPW12 units. ${ }^{22}$ In the present experiment, during the last 200 min on stream 
(Figure 5b), the total $\mathrm{NO}_{x}$ concentration was relatively close to that in the feed (only 14 ppm lower, whereas it was $71 \mathrm{ppm}$ lower at $100 \mathrm{~min}$ on stream), which means that the sample was still retaining only a limited amount of $\mathrm{NO}_{x}$ from the feed. By comparing the individual $\mathrm{NO}$ and $\mathrm{NO}_{2}$ concentrations in that final period with those in the period from 20 to 100 min on stream (1670 vs. 1643 ppm of NO, and 233 vs. $207 \mathrm{ppm}$ of $\mathrm{NO}_{2}$ ), it can be concluded that, in the period from 20 to $100 \mathrm{~min}$ on stream, both $\mathrm{NO}$ and $\mathrm{NO}_{2}$ were absorbed by the sample in similar proportions (27 ppm of $\mathrm{NO}$ absorbed per unit of time vs. $26 \mathrm{ppm}$ of $\mathrm{NO}_{2}$ ).
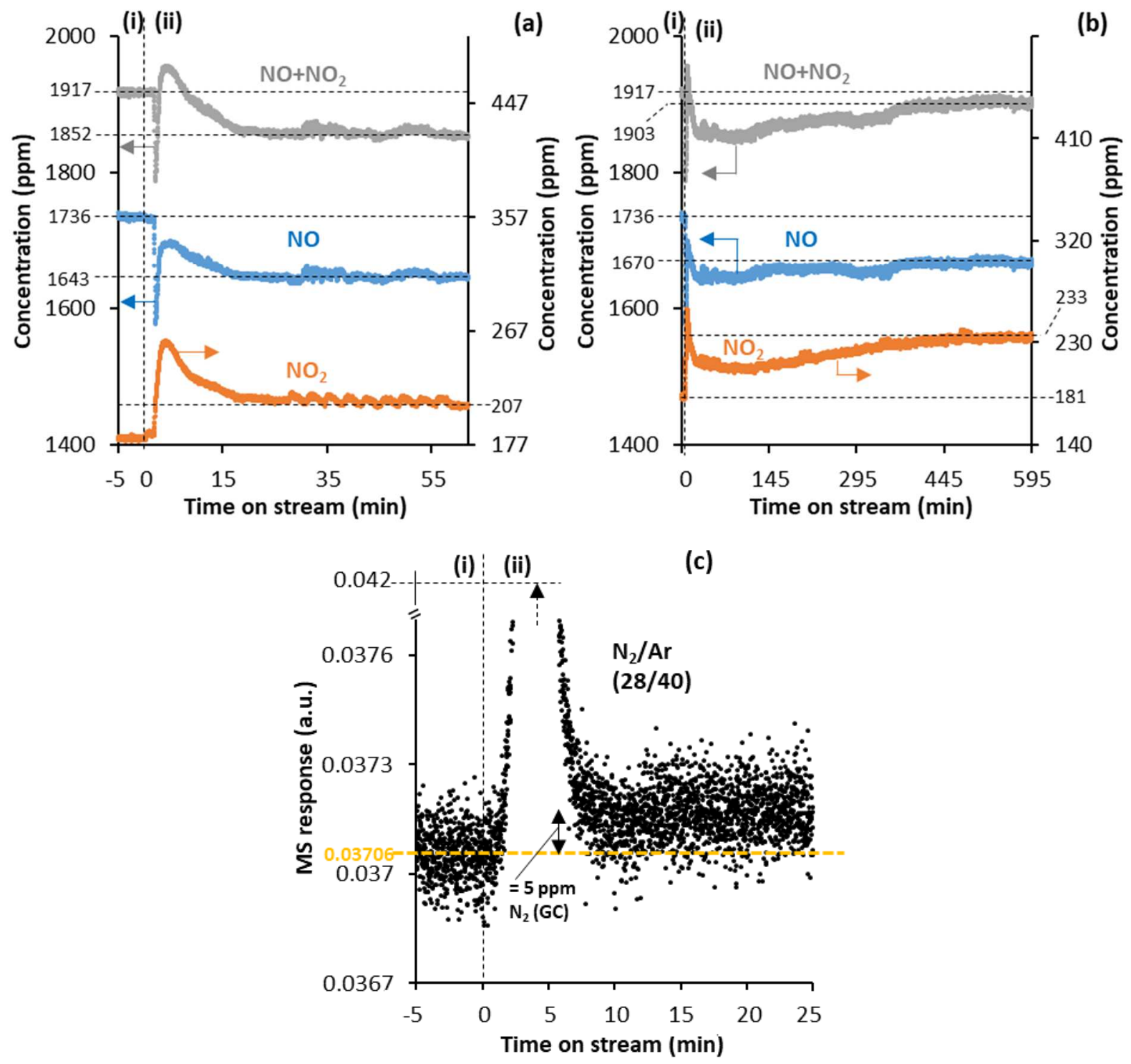

Figure 5. $\mathrm{NO}$ and $\mathrm{NO}_{2}$ concentrations recorded by the MKS MultiGas $2030 \mathrm{IR}$ analyzer (a-b) and mass to charge (m/z) ratio 28 associated with $\mathrm{N}_{2}$ normalized by the $\mathrm{m} / \mathrm{z} 40$ one associated with Ar recorded by the MS (c) as a function of time on stream in the $\mathrm{NO}_{\mathrm{x}}$ decomposition experiment with the P-HPW12 sample $\left(2.5 \mathrm{~g},<125 \mu \mathrm{m}, \mathrm{P}\right.$ standing for $\mathrm{NO}_{\mathrm{x}}$-pre-saturated $)$ at 380 ${ }^{\circ} \mathrm{C}$ and a reaction feed consisting of $\mathrm{NO}(\sim 2000 \mathrm{ppm})$ in $\mathrm{O}_{2}(5 \%)-\mathrm{Ar}(13 \%) / \mathrm{He}(50 \mathrm{mLNTP} / \mathrm{min})$. In (b), for the sake of clarity, the same data as in (a) is shown over a longer time scale. In (i), the reaction feed was analyzed without being contacted with the sample (upon flowing exclusively through lines at RT). In (ii), the reaction feed was continuously contacted with the sample at $380{ }^{\circ} \mathrm{C}$, and the outlet gas flow was analyzed over time on stream. The $\mathrm{N}_{2} / \mathrm{Ar}$ peak at around 5 min on stream has no analytical interest here. It is attributed to the release of air trapped in the valve that served for contacting the reaction feed with the sample. Its upper intensity was cut from the graph, as indicated by the rising arrow. This experiment with P-HPW12 was the third one over the same sample. The two first ones were carried out in the absence of $\mathrm{O}_{2}$ in the feed (Figure 4 and Figure $\mathrm{S} 7$, respectively). The P-HPW12 sample was previously heated from RT to $380{ }^{\circ} \mathrm{C}$ at $3{ }^{\circ} \mathrm{C} / \mathrm{min}$ under $\operatorname{Ar}(8 \%) / \mathrm{He}\left(50 \mathrm{~mL} \mathrm{NTP}_{\mathrm{min}}\right)$. 
The fact that the presence of $\mathrm{O}_{2}$ in the feed induced a diffusion of $\mathrm{NO}_{2}$ into the bulk of P-HPW12 is attributed to the relatively high concentration of $\mathrm{NO}_{2}$ in the feed under these conditions (181 ppm in Figure 5a-b vs. 7 ppm in Figure 4a, periods (i)). The fact that, at the same time, it also enabled the diffusion of NO into the bulk may be assigned to two possible origins. Firstly, NO might have been brought up into the bulk of HPW12 concomitantly with $\mathrm{NO}_{2}$ via the formation of $\mathrm{N}_{2} \mathrm{O}_{3}{ }^{25}$ Secondly, $\mathrm{O}_{2}$ might have reacted with $\mathrm{NO}$ at the surface of the crystals to form intermediate $\mathrm{NO}_{\mathrm{x}}{ }^{y_{-}}$adspecies being easily protonated by the protons located in the near-surface bulk of HPW12 (thereby regenerating $\mathrm{O}_{2}$ ) and consequently leading to the absorption of NO into the bulk of HPW12. ${ }^{19}$ Overall, the presence of $\mathrm{O}_{2}$ in the feed appears to be required for $\mathrm{NO}$ to form a species that is able to diffuse into the bulk of HPW12.

The diffusion of $\mathrm{NO}_{x}$ into the bulk of P-HPW12 led to the decomposition of $\mathrm{NO}_{x}$ from the feed and/or of $\mathrm{NO}_{x}$ pre-absorbed in the bulk into $\mathrm{N}_{2}$. Indeed, in period (ii) of Figure $5 \mathrm{c}$, following its initial peak centered at around $5 \mathrm{~min}$ on stream, attributed to the evacuation of traces of air trapped in the 4-way valve used for contacting the reaction feed with the sample, the $\mathrm{N}_{2} / \mathrm{Ar}$ trace stabilized at a higher level than that measured in period (i). As shown in Figure S8, the production of $\mathrm{N}_{2}$ remained stable for about $200 \mathrm{~min}$ on stream, before decreasing to the level measured in period (i) within the next $300 \mathrm{~min}$. According to $\mu$-GC measurements (the error associated to which is estimated to be about $1.6 \%$ ), about $5 \mathrm{ppm}$ of $\mathrm{N}_{2}$ were produced per unit of time in the first $200 \mathrm{~min}$ on stream, which corresponds to $10 \mathrm{ppm}$ of $\mathrm{NO}_{x}$ decomposed per unit of time. From 200 to $500 \mathrm{~min}$ on stream, while the $\mathrm{N}_{2} / \mathrm{Ar}$ signal was decreasing (Figure S8), the $\mathrm{NO}, \mathrm{NO}_{2}$, and total $\mathrm{NO}_{x}$ concentrations were increasing (Figure 5b). This shows that the deactivation of P-HPW12 was directly related to the decreasing capacity of its bulk to further incorporate $\mathrm{NO}_{x}$ species. To explain this finding, two non-exclusive hypotheses may be proposed. Firstly, once the $\mathrm{NO}_{x}$ from the feed were no longer able to react over the deactivated bulk HPW12 units, they accumulated inside the bulk until saturating it. In this hypothesis, the HPW12 units may have been deactivated following the two non-exclusive mechanisms proposed earlier in the present work: 1) the $\mathrm{O}$ vacancies in the heteropolyanions getting filled by $\mathrm{O}_{2}$ and/or $\mathrm{NO}_{2}$, and/or 2) the protons associated with the heteropolyanions getting poisoned by $\mathrm{NO}_{2}$ as $\mathrm{HNO}_{2}{ }^{+}$species. Secondly, once the $\mathrm{NO}_{x}$ species pre-absorbed in the bulk had all been consumed by the decomposition reaction with $\mathrm{NO}_{x}$ from the feed, the bulk was essentially emptied, and therefore no longer accessible. ${ }^{21}$

\subsection{Comparison of the $\mathrm{NO}_{x}$ decomposition activities of $\mathrm{N}-\mathrm{HPW} 12$ and $\mathrm{P}-\mathrm{HPW} 12$}

Table 1 qualitatively summarizes the activities observed over the N-HPW12 and P-HPW12 samples in the direct decomposition of continuously fed $\mathrm{NO}_{x}$ at $380{ }^{\circ} \mathrm{C}$ in the absence and in the presence of $\mathrm{O}_{2}$ in the reaction feed. In section 3.4.1, the role of pre-absorbed $\mathrm{NO}_{x}$ species in the activity of P-HPW12 in the decomposition of $\mathrm{NO}_{x}$ from the $\mathrm{O}_{2}$-containing reaction feed is discussed (by comparing the activities of N-HPW12 and P-HPW12 shown in Figure 2 vs. Figures 5 and S8, respectively). In section 
3.4.2, the activity of N-HPW12 in the absence of $\mathrm{O}_{2}$ in the reaction feed (Figure 1) is compared to that of P-HPW12 in the presence of $\mathrm{O}_{2}$ in the reaction feed (Figures 5 and S8) in terms of NO conversion and stability over time on stream.

Table 1. Qualitative summary of the activities observed over the N-HPW12 and P-HPW12 samples $(2.5 \mathrm{~g},<125 \mu \mathrm{m})$ in the direct decomposition of continuously fed $\mathrm{NO}_{x}$ at $380{ }^{\circ} \mathrm{C}$ in the absence and presence of $\mathrm{O}_{2}(5 \%)$ in the reaction feed (Figures $1-2,4-5$ and $\mathrm{S} 6$ to S8). The reaction feed contained $\mathrm{NO}(\sim 2000 \mathrm{ppm})$ in $\operatorname{Ar}(13 \%) / \mathrm{He}(50 \mathrm{~mL}$ NP $/ \mathrm{min}$ total flow rate). The NHPW12 and P-HPW12 samples were previously heated from RT to $380{ }^{\circ} \mathrm{C}$ at $10{ }^{\circ} \mathrm{C} / \mathrm{min}$ under $\mathrm{He}$ and at $3{ }^{\circ} \mathrm{C} / \mathrm{min}$ under $\operatorname{Ar}(8 \%) / \mathrm{He}$, respectively $\left(50 \mathrm{~mL}\right.$ TP/min). Unlike the $\mathrm{N}-\mathrm{HPW} 12$ sample, the P-HPW12 sample was pre-saturated with $\mathrm{NO}_{x}$ at $\mathrm{RT}$ ( $\mathrm{N}$ and $\mathrm{P}$ standing for non- $\mathrm{NO}_{x}$-pre-saturated and $\mathrm{NO}_{x}$-pre-saturated, respectively). "Min" are min of reaction, not including the $5 \mathrm{~min}$ in which the reaction feed was analyzed without being contacted with the sample, namely period (i) in Figures 1-2, 4-5 and S6 to S8.

\begin{tabular}{|c|c|c|}
\hline \multirow{2}{*}{ Reaction feed } & \multicolumn{2}{|c|}{ Concentration of $\mathrm{NO}_{x}$ decomposed into $\mathrm{N}_{2}$} \\
\cline { 2 - 3 } & Over N-HPW12 & Over P-HPW12 \\
\hline $\mathrm{O}_{2}$-free & $\begin{array}{c}\text { - Essentially decreasing } \\
\text { in the } 60 \text { min considered } \\
\text { - At 60 min, 30 ppm }\end{array}$ & 0 \\
\hline $\mathbf{O}_{\mathbf{2}}(\mathbf{5 \%}$ )-containing & 0 & $\begin{array}{c}\text { Stable at 10 ppm for 200 } \\
\text { min before decreasing to } 0 \\
\text { in 300 min }\end{array}$ \\
\hline
\end{tabular}

\subsubsection{The positive impact of the pre-saturation of $\mathrm{HPW1} 2$ with $N \mathrm{~N}_{x}$ species on its $N \mathrm{O}_{x}$ decomposition} activity in the presence of $\mathrm{O}_{2}$ in the reaction feed, and the balance between positive and deactivating impacts of $\mathrm{O}_{2}$

The second hypothesis proposed at the end of section 3.3.2 to account for the observed deactivation of P-HPW12, namely that a $\mathrm{NO}_{x}$-emptied HPW12 bulk is no longer accessible to $\mathrm{NO}_{x}$ from the feed, arises from the fact that $\mathrm{NO}_{x}$ were essentially unable to enter the bulk of the N-HPW12 sample at 380 ${ }^{\circ} \mathrm{C}$ despite the presence of $\mathrm{O}_{2}$ in the feed. This assumption is supported by the absence of plateau in the $\mathrm{NO}$ and $\mathrm{NO}_{2}$ concentration traces when the total $\mathrm{NO}_{x}$ concentration was significantly below that in the feed (when $\mathrm{NO}_{x}$ were retained by the sample), i.e. in the first $100 \mathrm{~min}$ on stream (Figure 2). Within this period, $\mathrm{NO}_{x}$ were essentially adsorbed onto the surface of N-HPW12, with a higher rate than that observed in the case of P-HPW12 (Figure 2 vs. Figure 5), as the surface of the latter had been already partly covered with $\mathrm{NO}_{x}$ species during the pre-saturation step at RT (Figure $2 v s$. Figure 5). Thus, the presence of pre-absorbed $\mathrm{NO}_{x}$ appears to be necessary for $\mathrm{NO}$ and $\mathrm{NO}_{2}$ to enter the bulk of HPW12 crystals at $380{ }^{\circ} \mathrm{C}$, unlike at RT (Figure 3). This suggests that, rather than depending on the temperature as a source of energy to overcome the activation barrier of bulk absorption, the ability of $\mathrm{NO}_{x}$ to enter the bulk depends on the temperature as a modulator of the balance between the strength of adsorption at the surface of the crystals and the activation energy required to enter the bulk. At $380{ }^{\circ} \mathrm{C}$, the adsorption of $\mathrm{NO}_{x}$ at the surface of N-HPW12 must be weaker than at RT, whereas the activation energy to enter its bulk is likely higher, due to the absence of structural water which requires the $\mathrm{NO}_{x}$ to open the way in-between the bulk HPW12 units. This makes the diffusion of $\mathrm{NO}_{x}$ into the bulk more difficult, unless 
the presence of pre-absorbed $\mathrm{NO}_{x}$ species has already made the diffusion pathway in-between the bulk HPW12 units accessible, as in the case of P-HPW12.

In summary, the different $\mathrm{NO}_{x}$ decomposition activities observed for the N-HPW12 and P-HPW12 samples at $380{ }^{\circ} \mathrm{C}$ in the presence of $\mathrm{O}_{2}$ in the feed (Figures 2 and 5 , respectively) resulted from a balance between the negative impact of $\mathrm{O}_{2}$ and/or $\mathrm{NO}_{2}$ deactivating the heteropolyanions and/or their associated protons, and the positive impact of $\mathrm{O}_{2}$ and/or $\mathrm{NO}_{2}$ initiating the diffusion of $\mathrm{NO}$ into the bulk of the HPW12 crystals. The latter positive impact took place to a noticeable extent only in the case of P-HPW12 (Figure 5), thanks to $\mathrm{NO}_{x}$ species pre-absorbed in the bulk of HPW12 having made the diffusion pathway in-between the HPW12 units accessible to the $\mathrm{NO}_{x}$ from the reaction feed. This explains that P-HPW12 exhibited a $\mathrm{NO}_{x}$ decomposition activity in the presence of $\mathrm{O}_{2}$ in the reaction feed, whereas N-HPW12 was found to be inactive in this reaction under the same conditions.

\subsubsection{Comparison of the $\mathrm{NO}_{x}$ decomposition activity of $\mathrm{N}-\mathrm{HPW} 12$ in the absence of $\mathrm{O}_{2}$ in the reaction} feed to that of $\mathrm{P}-\mathrm{HPW} 12$ in the presence of $\mathrm{O}_{2}$ in the reaction feed

The balance between the negative and positive impacts of $\mathrm{O}_{2}$ and/or $\mathrm{NO}_{2}$ described in section 3.4.1 was, however, still not sufficiently favorable for P-HPW12 to reach a $\mathrm{NO}_{x}$ decomposition activity in the presence of $\mathrm{O}_{2}$ in the reaction feed (Figure 5) as high as that recorded on N-HPW12 in the absence of $\mathrm{O}_{2}$ in the reaction feed (Figure 1). At $60 \mathrm{~min}$ of reaction, $10 \mathrm{ppm}$ of $\mathrm{NO}_{x}$ were decomposed over PHPW12 in the presence of $\mathrm{O}_{2}$ in the feed (Figures $5 \mathrm{c}$ and $\mathrm{S} 8$ ), whereas $30 \mathrm{ppm}$ of $\mathrm{NO}_{x}$ were decomposed over N-HPW12 in the absence of $\mathrm{O}_{2}$ (Figure 1). Nevertheless, P-HPW12 exhibited a stable $\mathrm{NO}_{x}$ decomposition activity for as long as $200 \mathrm{~min}$, thanks to the increased fraction of accessible HPW12 units whose deactivation was likely limited by $\mathrm{NO}_{x}$ diffusion inside the bulk, ${ }^{22}$ whereas N-HPW12 showed a continuously decreasing activity in the considered $60 \mathrm{~min}$ of reaction. Indeed, even in the absence of $\mathrm{O}_{2}$ intentionally added into the feed, the latter still contained a few ppm of deactivating $\mathrm{NO}_{2}$ and traces of $\mathrm{O}_{2}$, as well as $\mathrm{O}_{2}$ that was produced along with the decomposition of NO over N-HPW12, which might have also led to the progressive filling of the $\mathrm{O}$ vacancies in the HPW12 units and thus to the deactivation of the sample. Such a progressive filling of the O vacancies might explain the progressive increase of the $\mathrm{O}_{2} / \mathrm{Ar}$ signal from 8 min on stream in Figure 1c (the Keggin units exhibiting less and less $\mathrm{O}$ vacancies to be filled as the decomposition reaction proceeded).

\subsection{Identifying the active sites of HPW12 in the direct decomposition of $\mathrm{NO}_{x}$, and possible origins of} their deactivation

Figure 6 shows the in situ DRIFT difference spectra at steady state of N-HPW12 at $380{ }^{\circ} \mathrm{C}$ under a $50 \mathrm{~mL}_{\mathrm{NTP}} / \mathrm{min}$ feed of $\mathrm{NO}(\sim 2000 \mathrm{ppm})$ in $\mathrm{Ar}(40 \%) / \mathrm{He}$ which first contained no $\mathrm{O}_{2}$ (spectrum 1, NO) and subsequently contained $5 \%$ of $\mathrm{O}_{2}$ (spectrum $2, \mathrm{NO}+\mathrm{O}_{2}$ ). For the sake of clarity, panels a and b show the same spectra in two different spectral regions. Both difference spectra were obtained by subtraction 
of the last spectrum recorded at $380{ }^{\circ} \mathrm{C}$ under $\operatorname{Ar}(40 \%) / \mathrm{He}$ before $\mathrm{NO}$ was added into the feed. $\mathrm{N}$ HPW 12 was previously heated from RT to $380{ }^{\circ} \mathrm{C}$ at $3{ }^{\circ} \mathrm{C} / \mathrm{min}$ under $\operatorname{Ar}(40 \%) / \mathrm{He}\left(50 \mathrm{~mL} \mathrm{NTP}_{\mathrm{NP}} / \mathrm{min}\right)$.

Both difference spectra show a positive band at $2261 \mathrm{~cm}^{-1}$, and a broad negative band centered at 3230 $\mathrm{cm}^{-1}$. In the presence of $\mathrm{O}_{2}$ in the feed (spectrum 2 in Figure 6), the area of these two bands is 4.8 and 1.3 times higher, respectively, than in the absence of $\mathrm{O}_{2}$ in the feed (spectrum 1 in Figure 6). In earlier studies about the absorption of $\mathrm{NO}$ and/or $\mathrm{NO}_{2}$ into the bulk of HPW12 at temperatures around $150{ }^{\circ} \mathrm{C}$, the band at $2261 \mathrm{~cm}^{-1}$ was assigned to $\mathrm{v}(\mathrm{N}=\mathrm{O})$ stretches within both $\mathrm{NOH}^{+}$and $\mathrm{HNO}_{2}{ }^{+}$species. ${ }^{19,20}$ The negative band at $3230 \mathrm{~cm}^{-1}$ was neither shown nor commented in earlier literature studies. It is attributed here to the consumption of HPA protons upon $\mathrm{NOH}^{+}$and/or $\mathrm{HNO}_{2}{ }^{+}$formation. The higher areas of the bands at 2261 and $3230 \mathrm{~cm}^{-1}$ in the presence of $\mathrm{O}_{2}$ in the feed can be attributed to two non-exclusive origins. Firstly, it may result from the 26 times higher concentration of $\mathrm{NO}_{2}$ in the $\mathrm{O}_{2}$-containing feed (181 ppm vs. 7 ppm in Figures 5a-b and 4a, respectively), which led to an increase of the concentration of $\mathrm{HNO}_{2}{ }^{+}$adspecies, that may have reached the near-surface bulk of the HPW12 crystals to a little extent. ${ }^{25}$ Secondly, it may result from the formation of $\mathrm{NOH}^{+}$species in the near-surface bulk of HPW12, thanks to either $\mathrm{NO}_{2}$ as a carrier or $\mathrm{O}_{2}$ having reacted with $\mathrm{NO}$ at the surface to form intermediate $\mathrm{NO}_{\mathrm{x}}{ }^{y-}$ adspecies that are potentially required to initiate bulk absorption. ${ }^{19}$ 


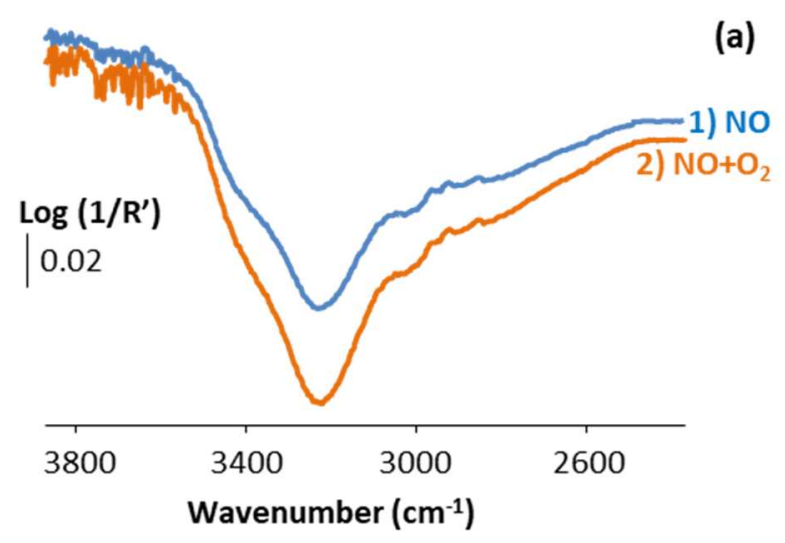

(b)

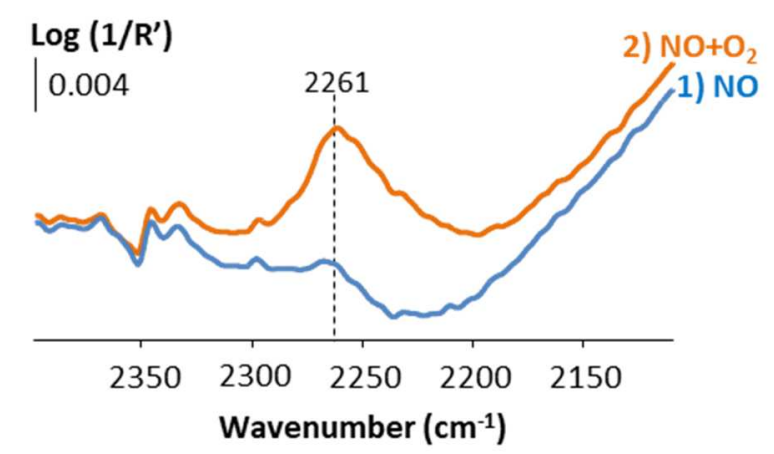

Figure 6. In situ DRIFT difference spectra of N-HPW12 ( $\mathrm{N}$ standing for non- $\mathrm{NO}_{x}$-pre-saturated) at $380{ }^{\circ} \mathrm{C}$ under a feed of NO ( $2000 \mathrm{ppm})$ in $\operatorname{Ar}(40 \%) / \mathrm{He}(50 \mathrm{mLNTP} / \mathrm{min}) 1)$ since $12 \mathrm{~h}$ and 2) $8 \mathrm{~h}$ after adding $\mathrm{O}_{2}(5 \%)$ into the feed, in the spectral regions of (a) structural $\mathrm{O}-\mathrm{H}^{+}$stretches and (b) $\mathrm{N}=\mathrm{O}$ stretches within $\mathrm{NOH}^{+}$and $\mathrm{HNO}_{2}{ }^{+}$species. N-HPW12 was heated from RT to 380 ${ }^{\circ} \mathrm{C}$ at $3{ }^{\circ} \mathrm{C} / \mathrm{min}$ under $\operatorname{Ar}(40 \%) / \mathrm{He}(50 \mathrm{~mL}$ NTP $/ \mathrm{min})$. Both difference spectra were obtained by subtraction of the last spectrum recorded at $380{ }^{\circ} \mathrm{C}$ under $\operatorname{Ar}(40 \%) / \mathrm{He}$ before $\mathrm{NO}$ was added into the feed. $\log (1 / \mathrm{R}$ ') is expressed in arbitrary units, with the relative reflectance $\mathrm{R}^{\prime}=\mathrm{I}_{\text {sample }} / \mathrm{I}_{\text {(reference sample) }}$.

A similar study was performed on a HPW12 sample which was beforehand saturated with $\mathrm{NO} / \mathrm{NO}_{2}$ at RT to provide a P-HPW12 sample, and then heated from RT to $380{ }^{\circ} \mathrm{C}$ at $3{ }^{\circ} \mathrm{C} / \mathrm{min}$ under $\operatorname{Ar}(40 \%) / \mathrm{He}$ (50 $\left.\mathrm{mL}_{\mathrm{NTP}} / \mathrm{min}\right)$. At $380{ }^{\circ} \mathrm{C}$, the P-HPW12 sample was exposed to an $\mathrm{O}_{2}$-free feed of $\mathrm{NO}(\sim 2000 \mathrm{ppm})$ in $\operatorname{Ar}(40 \%) / \mathrm{He}\left(50 \mathrm{~mL}_{\mathrm{NTP}} / \mathrm{min}\right)$ (in situ DRIFT difference spectra shown in Figure S9, panel 1). The PHPW12 sample was then purged under $\operatorname{Ar}(40 \%) / \mathrm{He}(50 \mathrm{~mL} \mathrm{NTP} / \mathrm{min})$ before exposure to a feed of NO ( $2000 \mathrm{ppm})$ in $\mathrm{O}_{2}(5 \%)-\mathrm{Ar}(40 \%) / \mathrm{He}(50 \mathrm{~mL}$ NTP $/ \mathrm{min})$. Figure 7 shows the in situ DRIFT difference spectra of P-HPW12 at $380{ }^{\circ} \mathrm{C}$ as a function of time of exposure to the $\mathrm{O}_{2}$-containing NO feed, in the spectral region of $\mathrm{N}=\mathrm{O}$ stretches within $\mathrm{NOH}^{+}$and $\mathrm{HNO}_{2}{ }^{+}$species. During the exposures to the two $\mathrm{NO}$ feeds at $380{ }^{\circ} \mathrm{C}$, the difference spectra were obtained by subtraction of the last spectrum recorded at 380 ${ }^{\circ} \mathrm{C}$ under $\operatorname{Ar}(40 \%) / \mathrm{He}$ before the respective NO feed was contacted with the P-HPW12 sample.

The difference spectra (d-spectra hereafter) recorded within the first 10 min under the $\mathrm{O}_{2}$-free NO feed (Figure S9, panel 1) do not show the appearance of any IR absorption contribution. The d-spectrum recorded after $30 \mathrm{~min}$ on stream shows the appearance of a slight negative band at $2261 \mathrm{~cm}^{-1}$, which was found to remain essentially unchanged at longer exposures to the $\mathrm{O}_{2}$-free $\mathrm{NO}$ feed (d-spectra at 60 and 80 min in Figure S9, panel 1). In contrast, on the d-spectra recorded under the $\mathrm{O}_{2}$-containing NO feed (Figure 7), a sharp negative band was quickly observed at $2261 \mathrm{~cm}^{-1}$ (d-spectrum at $2 \mathrm{~min}$ ). The area of 
this band then continuously decreased until the end of the experiment (d-spectra from 4 to $900 \mathrm{~min}$, Figure 7). From 2 to 34 min on stream, it remained higher than that on the last d-spectrum recorded under the $\mathrm{O}_{2}$-free $\mathrm{NO}$ feed (Figure S9, panel 2 vs. panel 1). At longer exposures to the $\mathrm{O}_{2}$-containing NO feed (d-spectra from $60 \mathrm{~min}$ in Figure 7), the area of the band at $2261 \mathrm{~cm}^{-1}$ became lower than that on the last d-spectrum recorded under the $\mathrm{O}_{2}$-free NO feed (Figure S9, panel 1), without however reaching zero on the final spectrum at 900 min on stream.

The negative band at $2261 \mathrm{~cm}^{-1}$ indicates the disappearance of $\mathrm{NOH}^{+}$and/or $\mathrm{HNO}_{2}{ }^{+}$species which had been stored in the bulk of the sample during its pre-exposure to $\mathrm{NO}_{x}$ at $\mathrm{RT}$, due to their desorption and/or reaction under the $\mathrm{NO}-\mathrm{O}_{2}$ containing feed. The limited disappearance of pre-absorbed $\mathrm{NOH}^{+}$and/or $\mathrm{HNO}_{2}{ }^{+}$species under the $\mathrm{O}_{2}$-free $\mathrm{NO}$ feed (Figure $\mathrm{S}$ 9, panel 1) can be attributed to the slight desorption of such species in agreement with the release of $\mathrm{NO}_{x}$ species recorded in Figure 4a and the absence of $\mathrm{N}_{2}$ formation (Figure $4 \mathrm{~b}$ ). In contrast, the sharp disappearance of pre-absorbed $\mathrm{NOH}^{+}$and/or $\mathrm{HNO}_{2}{ }^{+}$ species under the $\mathrm{O}_{2}$-containing feed (Figure 7) is rather attributed to their reaction as supported by the presence of $\mathrm{N}_{2}$ in the effluent of the corresponding $\mathrm{NO}$ decomposition experiment described in section 3.2 (Figure 5c). The latter experiment showed that the presence of $\mathrm{O}_{2}$ in the reaction feed allowed $\mathrm{NO}_{x}$ from the latter feed to enter into the bulk of the sample, which led to $\mathrm{NO}_{x}$ decomposition into $\mathrm{N}_{2}$. The present DRIFT results show that this decomposition process relied on both the $\mathrm{NO}_{x}$ from the feed and the $\mathrm{NO}_{x}$ species pre-absorbed in the bulk. The $\mathrm{NO}_{x}$ from the feed reacted over the HPW12 units with the involvement of pre-absorbed $\mathrm{NOH}^{+}$species $\left(\mathrm{NO}_{\text {gas }}+\mathrm{NOH}^{+}=\mathrm{N}_{2}+\mathrm{O}_{2}+\mathrm{H}^{+}\right.$, or $\mathrm{NO}_{\text {gas }}+\mathrm{H}^{+}=\mathrm{NOH}^{+}$ followed by $\mathrm{NOH}^{+}+\mathrm{NOH}^{+}=\mathrm{N}_{2}+\mathrm{O}_{2}+2 \mathrm{H}^{+}$). The involvement of pre-absorbed $\mathrm{HNO}_{2}{ }^{+}$species seems unlikely in view of the deactivating impact of $\mathrm{NO}_{2}$ demonstrated in section 3.3.2. Hence, the present data suggest that $\mathrm{NOH}^{+}$species are important intermediates in the direct decomposition of $\mathrm{NO}_{x}$ over HPW 12 at $380{ }^{\circ} \mathrm{C}$, which thus relies on the protons of HPW12.

The fact that the band at $2261 \mathrm{~cm}^{-1}$ became less and less negative with increasing time on stream under the $\mathrm{O}_{2}$-containing $\mathrm{NO}$ feed (Figure 7) indicates that unreactive $\mathrm{NOH}^{+}$and/or $\mathrm{HNO}_{2}{ }^{+}$species were formed/adsorbed on the HPW12 units along with the reaction of pre-absorbed $\mathrm{NOH}^{+}$species with $\mathrm{NO}_{x}$ from the feed. This accumulation of unreactive $\mathrm{NOH}^{+}$and/or $\mathrm{HNO}_{2}{ }^{+}$species may have occurred according to two non-exclusive mechanisms. Firstly, along with the consumption of $\mathrm{NOH}^{+}$species through their reaction with $\mathrm{NO}_{x}$ from the feed, the regenerated protons might have been poisoned with $\mathrm{NO}_{2}$ by forming unreactive $\mathrm{HNO}_{2}{ }^{+}$species. Secondly, considering that the lacunary heteropolyanions might act as reductants in the direct decomposition of $\mathrm{NO}_{x}$ over HPW12, as proposed earlier in section 3.1.2, $\mathrm{NO}_{2}$ and/or $\mathrm{O}_{2}$ might have oxidized the heteropolyanions, thereby making them non-reductive and thus inactive in the direct decomposition of $\mathrm{NO}_{x}$ from the feed, and leading to the accumulation of $\mathrm{NOH}^{+}$species which were no longer able to react. Through the first and/or the second mechanism, this accumulation of unreactive species finally contributed to the deactivation of P-HPW12 observed in section 3.3.2 (Figures 5a-b and S8). 


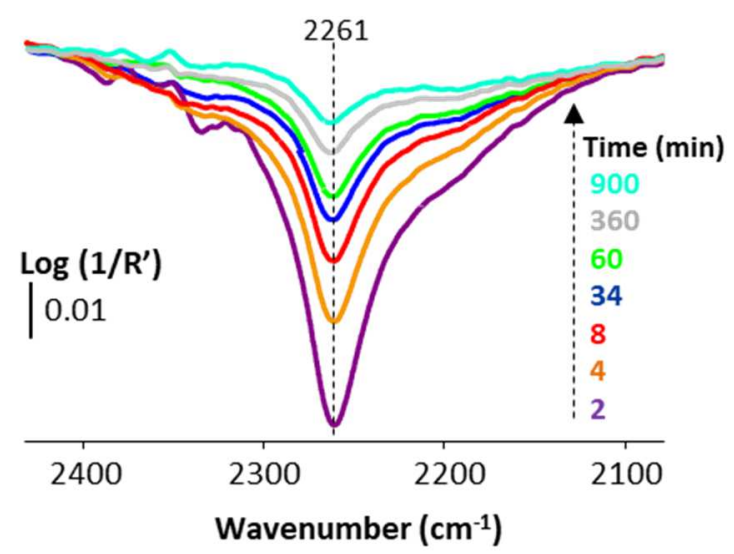

Figure 7. In situ DRIFT difference spectra of P-HPW12 (P standing for $\mathrm{NO}_{x}$-pre-saturated) at $380{ }^{\circ} \mathrm{C} v$ s. time of exposure to a feed of $\mathrm{NO}(\sim 2000 \mathrm{ppm})$ in $\mathrm{O}_{2}(5 \%)-\mathrm{Ar}(40 \%) / \mathrm{He}(50 \mathrm{mLNTP} / \mathrm{min})$, in the spectral region of $\mathrm{N}=\mathrm{O}$ stretches within $\mathrm{NOH}^{+}$and $\mathrm{HNO}_{2}{ }^{+}$species. P-HPW12 was heated from RT to $380{ }^{\circ} \mathrm{C}$ at $3{ }^{\circ} \mathrm{C} / \mathrm{min}$ under $\operatorname{Ar}(40 \%) / \mathrm{He}(50 \mathrm{~mL} \mathrm{NTP} / \mathrm{min})$. All difference spectra were obtained by subtraction of the last spectrum at $380{ }^{\circ} \mathrm{C}$ under $\operatorname{Ar}(40 \%) / \mathrm{He}$ measured before $\mathrm{NO}$ and $\mathrm{O}_{2}$ were added into the feed. $\log \left(1 / R^{\prime}\right)$ is expressed in arbitrary units, with the relative reflectance $R^{\prime}=I_{\text {sample }} / I_{(\text {reference sample) }}$.

\section{Conclusions}

For the first time, the activity of $\mathrm{H}_{3} \mathrm{PW}_{12} \mathrm{O}_{40}$ (HPW12) in the direct decomposition of $\mathrm{NO}_{x}$ was investigated under continuous $\mathrm{NO}_{x}$ feeding, at $380^{\circ} \mathrm{C}$. From the recorded $\mathrm{NO}$ decomposition and in situ DRIFT data, the observed $\mathrm{NO}_{x}$ decomposition activity of HPW12 was deduced to occur either through the reaction of two neighbouring $\mathrm{NOH}^{+}$adspecies, or through the reaction of one $\mathrm{NOH}^{+}$adspecies with gas phase NO. The presence of $\mathrm{NO}_{2}$ - either in the reaction feed due to the presence of $\mathrm{O}_{2}$ or in the bulk of the sample - was found to deactivate HPW12, likely because $\mathrm{NO}_{2}$ poisoned the protons by forming unreactive $\mathrm{HNO}_{2}{ }^{+}$species. Nevertheless, the presence of $\mathrm{O}_{2}-$ in the feed and/or generated by the decomposition process - was also found to have a positive impact, namely to initiate the diffusion of $\mathrm{NO}_{x}$ into the bulk of the HPW12 crystals. However, this diffusion process effectively took place only when the bulk of HPW12 already contained $\mathrm{NO}_{x}$ beforehand pre-absorbed at RT, i.e. when the HPW12 crystals were still hydrated. Indeed, at $380{ }^{\circ} \mathrm{C}$, the pre-absorbed $\mathrm{NO}_{x}$ species preserved the diffusion pathway in-between the bulk HPW12 units and therefore allowed the diffusion of the $\mathrm{NO}_{x}$ from the feed and their reaction with $\mathrm{NOH}^{+}$species. In the presence of $\mathrm{O}_{2}$ in the feed, the bulk-type reaction allowed the otherwise inactive HPW12 material to remain active for 8 hours. By providing the key parameters involved in the $\mathrm{NO}_{x}$ decomposition process over $\mathrm{HPW} 12$ at $380{ }^{\circ} \mathrm{C}$, the present work paves the way for future investigations in order to further improve the lifetime and activity of HPW12. Future investigations may focus, for instance, on tuning the chemical composition of the surface and/or bulk heteropolyanions in order to make the HPA more resistant to poisoning by $\mathrm{O}_{2}$ and/or $\mathrm{NO}_{2}$.

\section{Supporting information}

Structural water desorption profiles upon heating the two HPW12 samples from RT to the reaction temperature $380{ }^{\circ} \mathrm{C}$ under inert atmosphere; Full in situ DRIFT absorbance spectra of the two HPW12 
samples under various conditions; $\mathrm{NO}$ and $\mathrm{NO}_{2}$ concentrations and $\mathrm{N}_{2} / \mathrm{Ar}$ trace recorded $v s$. time on stream in the blank NO decomposition experiments with only quartz wool in the reactor; $\mathrm{H}_{2} \mathrm{O}$ concentration recorded vs. time on stream during the pre-saturation of P-HPW12 with $\mathrm{NO}_{x}$ at RT; NO and $\mathrm{NO}_{2}$ concentrations and $\mathrm{N}_{2} / \mathrm{Ar}$ trace recorded $v s$. time on stream upon heating P-HPW12 from RT to the reaction temperature $380{ }^{\circ} \mathrm{C}$ under inert atmosphere; Comparison of the $\mathrm{NO}$ and $\mathrm{NO}_{2}$ concentrations recorded $v s$. time on stream in the two successive $\mathrm{NO}$ decomposition experiments over P-HPW 12 at $380{ }^{\circ} \mathrm{C}$ in the absence of $\mathrm{O}_{2}$ in the feed; $\mathrm{N}_{2} / \mathrm{Ar}$ trace recorded $v s$. time on stream in the NO decomposition experiment over P-HPW12 at $380{ }^{\circ} \mathrm{C}$ in the presence of $\mathrm{O}_{2}$ in the feed, over a longer time scale (600 $\mathrm{min}$ ) than shown in the manuscript (30 min); Detailed comparison of the in situ DRIFT difference spectra in the region of $\mathrm{N}=\mathrm{O}$ stretches within $\mathrm{NOH}^{+}$and $\mathrm{HNO}_{2}{ }^{+}$species measured in the experiments over P-HPW12 at $380{ }^{\circ} \mathrm{C}$ in the absence $v s$. presence of $\mathrm{O}_{2}$ in the feed.

\section{Acknowledgements}

This work has benefited from a funding managed by the French National Research Agency (DECOMPNOx project: ANR-18-CE07-0002). The authors acknowledge Jean-Marc Krafft (Sorbonne Université, CNRS, Laboratoire de Réactivité de Surface) for the technical support in in situ DRIFT experiments.

\section{Author information}

\section{Corresponding authors}

*E-mails: josefine.schnee@upmc.fr, josischnee@hotmail.com, cyril.thomas@upmc.fr.

\section{ORCID numbers}

Josefine Schnee: 0000-0001-8521-9922

Laurent Delannoy: 0000-0002-3263-5065

Guylène Costentin: 0000-0003-1559-6890

Cyril Thomas: 0000-0003-4224-6095

\section{Competing interests}

The authors declare no competing interests.

\section{References}

1. Kozhevnikov, I. V. Sustainable heterogeneous acid catalysis by heteropoly acids. J. Mol. Catal. A: Chem. 2007, 262, 86-92.

2. Kozhevnikov, I. V. Catalysis by heteropoly acids and multicomponent polyoxometalates in liquid-phase reactions. Chem. Rev. 1998, 98, 171-198. 
3. Ganapathy, S.; Fournier, M.; Paul, J. F.; Delevoye, L.; Guelton, M.; Amoureux, J. P. Location of protons in anhydrous Keggin heteropolyacids $\mathrm{H}_{3} \mathrm{PMo}_{12} \mathrm{O}_{40}$ and $\mathrm{H}_{3} \mathrm{PW}_{12} \mathrm{O}_{40}$ by $1 \mathrm{H}\{31 \mathrm{P}\} / 31 \mathrm{P}\{1 \mathrm{H}\}$ REDOR NMR and DFT quantum chemical calculations. J. Amer. Chem. Soc. 2002, 124, 7821-7828.

4. Li, G.; Ding, Y.; Wang, J.; Wang, X.; Suo, J. New progress of Keggin and Wells-Dawson type polyoxometalates catalyze acid and oxidative reactions. J. Mol. Catal. A: Chem. 2007, 262, 67-76. 5. Bielański, A.; Lubańska, A.; Micek-Ilnicka, A.; Poźniczek, J. Polyoxometalates as the catalysts for tertiary ethers MTBE and ETBE synthesis. Coord. Chem. Rev. 2005, 249, 2222-2231.

6. Janik, M. J.; Campbell, K. A.; Bardin, B. B.; Davis, R. J.; Neurock, M. A computational and experimental study of anhydrous phosphotungstic acid and its interaction with water molecules. Appl. Catal., A 2003, 256, 51-68.

7. Zhang, H.; Zheng, A.; Yu, H.; Li, S.; Lu, X.; Deng, F. Formation, location, and photocatalytic reactivity of methoxy species on Keggin $12-\mathrm{H}_{3} \mathrm{PW}_{12} \mathrm{O}_{40}$ : A joint solid-state NMR spectroscopy and DFT calculation study. J. Phys. Chem. C 2008, 112, 15765-15770.

8. Sugii, T.; Ohnishi, R.; Zhang, J.; Miyaji, A.; Kamiya, Y.; Okuhara, T. Acidity-attenuated heteropolyacid catalysts: Acidity measurement using benzonitrile-TPD and catalytic performance in the skeletal isomerization of n-heptane. Catal. Today 2006, 116, 179-183.

9. Chen, N.; Yang, R. T. Activation of nitric oxide by heteropoly compounds: Structure of nitricoxide linkages in tungstophosphoric acid with Keggin units. J. Catal. 1995, 157, 76-86.

10. Reddy, G. K.; Ling, C.; Peck, T. C.; Jia, H. Understanding the chemical state of palladium during the direct $\mathrm{NO}$ decomposition - influence of pretreatment environment and reaction temperature. RSC Adv. 2017, 7, 19645-19655.

11. Haneda, M.; Hamada, H. Recent progress in catalytic NO decomposition. C. R. Chim. 2016, 19, 1254-1265.

12. Reddy, G. K.; Peck, T. C.; Roberts, C. A. $\mathrm{CeO}_{2}-\mathrm{M}_{\mathrm{x}} \mathrm{O}_{\mathrm{y}}(\mathrm{M}=\mathrm{Fe}, \mathrm{Co}, \mathrm{Ni}$, and $\mathrm{Cu})$-based oxides for direct NO decomposition. J. Phys. Chem. C 2019, 123, 28695-28706.

13. Imanaka, N.; Masui, T. Advances in direct $\mathrm{NO}_{x}$ decomposition catalysts. Appl. Catal., A 2012, 431-432, 1-8.

14. Song, Y.-J.; Jesús, Y. M. L.-D.; Fanson, P. T.; Williams, C. T. Kinetic evaluation of direct NO decomposition and $\mathrm{NO}-\mathrm{CO}$ reaction over dendrimer-derived bimetallic $\mathrm{Ir}-\mathrm{Au} / \mathrm{Al}_{2} \mathrm{O}_{3}$ catalysts. Appl. Catal., B 2014, 154-155, 62-72.

15. Modén, B.; Da Costa, P.; Fonfé, B.; Lee, D. K.; Iglesia, E. Kinetics and mechanism of steadystate catalytic NO decomposition reactions on Cu-ZSM5. J. Catal. 2002, 209, 75-86.

16. Wang, X.; Sigmon, S. M.; Spivey, J. J.; Lamb, H. H. Support and particle size effects on direct NO decomposition over platinum. Catal. Today 2004, 96, 11-20.

17. Peck, T. C.; Reddy, G. K.; Roberts, C. A. Monolayer supported $\mathrm{CuO}_{\mathrm{x}} / \mathrm{Co}_{3} \mathrm{O}_{4}$ as an active and selective low temperature $\mathrm{NO}_{x}$ decomposition catalyst. Catal. Sci. Technol. 2019, 9, 1132-1140. 
18. Kozhevnikov, I. V. Sustainable heterogeneous acid catalysis by heteropoly acids. J. Mol. Catal. A: Chem. 2007, 262, 86-92.

19. Herring, A. M.; McCormick, R. L. In Situ infrared study of the absorption of nitric oxide by 12tungstophosphoric acid. J. Phys. Chem. B 1998, 102, 3175-3184.

20. Weng, X.; Dai, X.; Zeng, Q.; Liu, Y.; Wu, Z. DRIFT studies on promotion mechanism of $\mathrm{H}_{3} \mathrm{PW}_{12} \mathrm{O}_{40}$ in selective catalytic reduction of $\mathrm{NO}$ with $\mathrm{NH}_{3}$. J. Colloid Interface Sci. 2016, 461, 9-14.

21. Schnee, J.; Gaigneaux, E. M. Elucidating and exploiting the chemistry of Keggin heteropolyacids in the methanol-to-DME conversion: enabling the bulk reaction thanks to operando Raman. Catal. Sci. Technol. 2017, 7, 817-830.

22. Schnee, J.; Gaigneaux, E. M. Lifetime of the $\mathrm{H}_{3} \mathrm{PW}_{12} \mathrm{O}_{40}$ heteropolyacid in the methanol-toDME process: A question of pre-treatment. Appl. Catal., A 2017, 538, 174-180.

23. Yang, R. T.; Chen, N. A new approach to decomposition of nitric oxide using sorbent/catalyst without reducing gas: Use of heteropoly compounds. Ind. Eng. Chem. Res. 1994, 33, 825-831.

24. Sirita, J.; Phanichphant, S.; Meunier, F. C. Quantitative analysis of adsorbate concentrations by diffuse reflectance FT-IR. Anal. Chem. 2007, 79, 3912-3918.

25. Belanger, R.; Moffat, J. B. A comparative study of the adsorption and reaction of nitrogen oxides on 12-tungstophosphoric, 12-tungstosilicic, and 12-molybdophosphoric acids. J. Catal. 1995, 152, 179188.

\section{TOC image}

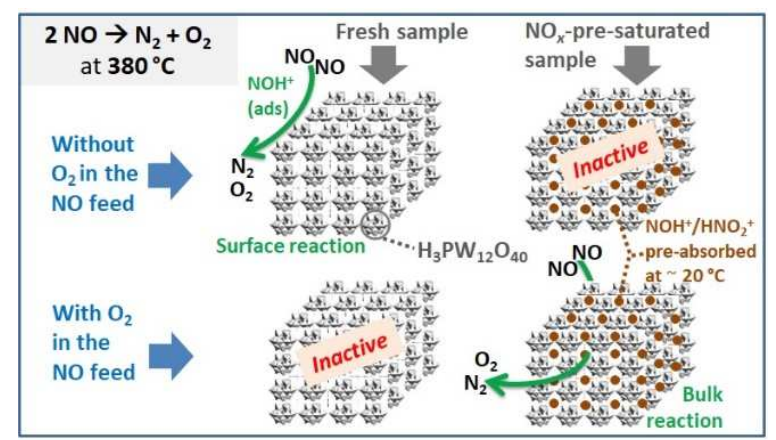




\section{Unravelling the Direct Decomposition of $\mathrm{NO}_{x}$ over Keggin Heteropolyacids and their Deactivation Using a Combination of Gas-IR/MS and in Situ DRIFT}

Josefine Schnee, * Laurent Delannoy, Guylène Costentin, and Cyril Thomas*

Sorbonne Université, CNRS, Laboratoire de Réactivité de Surface (LRS), F-75005 Paris, France.

*Corresponding authors: josefine.schnee@upmc.fr, josischnee@hotmail.com,cyril.thomas@upmc.fr.

\section{Supplementary information}

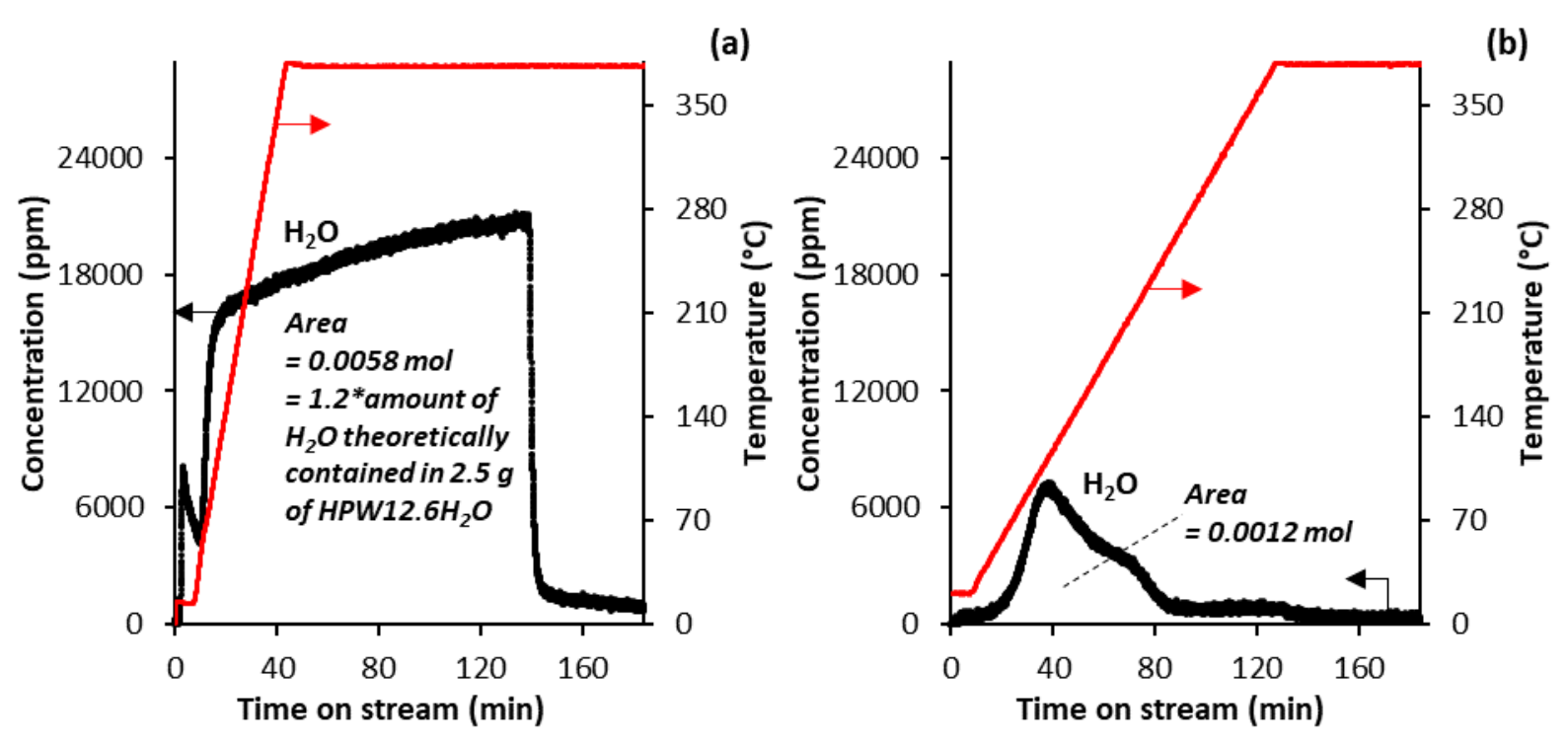

Figure S1. $\mathrm{H}_{2} \mathrm{O}$ concentration and temperature trace recorded by the MKS MultiGas $2030 \mathrm{IR}$ analyzer as a function of time on stream upon heating (a) the N-HPW12 sample from RT to $380{ }^{\circ} \mathrm{C}$ at $10{ }^{\circ} \mathrm{C} / \mathrm{min}$ under $\mathrm{He}(50 \mathrm{~mL} \mathrm{NT} / \mathrm{min})$, and (b) the PHPW 12 sample from RT to $380{ }^{\circ} \mathrm{C}$ at $3{ }^{\circ} \mathrm{C} / \mathrm{min}$ under $\operatorname{Ar}(8 \%) / \mathrm{He}(50 \mathrm{mLNTP} / \mathrm{min})$. 


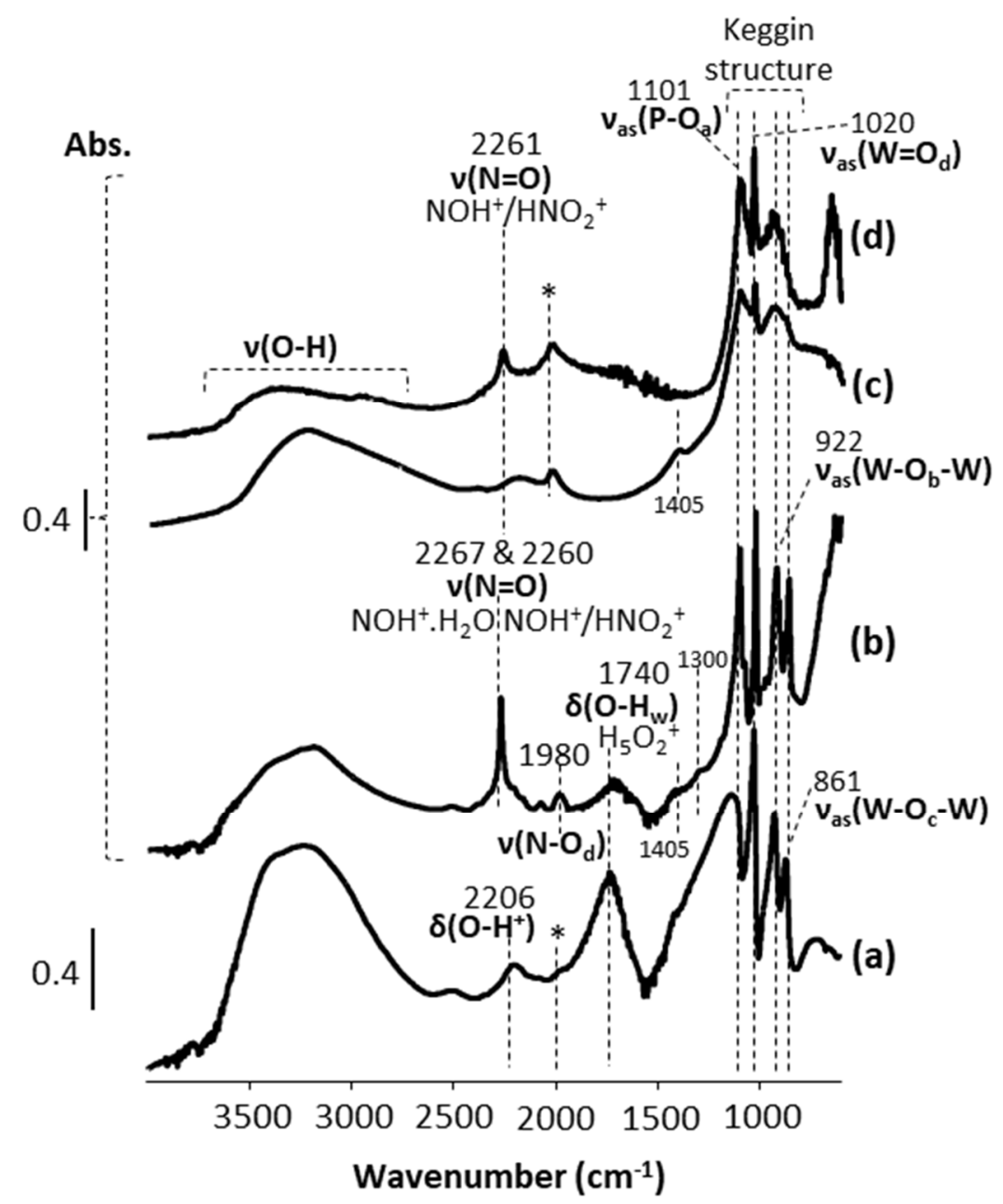

Figure S2. In situ DRIFT spectra of (a,c) N-HPW12 and (b,d) P-HPW12, at (a-b) RT and (c-d) $380{ }^{\circ} \mathrm{C}$, under $50 \mathrm{~mL} \mathrm{NTP}_{\mathrm{NP}} / \mathrm{min}$ of (a,c-d) $\operatorname{Ar}(40 \%) / \mathrm{He}$ and (b) $\mathrm{NO}(\sim 2000 \mathrm{ppm})$ in $\mathrm{O}_{2}(5 \%)-\mathrm{Ar}(40 \%) / \mathrm{He}$ (since $48 \mathrm{~h}$, i.e. at the end of the pre-treatment yielding the P-HPW12 sample). Spectra (c) and (d) were measured after heating the samples from RT to $380{ }^{\circ} \mathrm{C}$ at $3{ }^{\circ} \mathrm{C} / \mathrm{min}$ under $\operatorname{Ar}(40 \%) / H e$. "Abs." means absorbance, and it is expressed in arbitrary units. "O- $\mathrm{H}_{\mathrm{w}}$ " means $\mathrm{O}-\mathrm{H}$ within water. The band marked with a star (*) on spectra (a), (c) and (d) is not attributed in the literature, to our knowledge. Within the fingerprint of the Keggin structure, due to a saturation effect, the bands are shifted to higher wavenumbers as compared to their equivalents on the spectra of HPW12 diluted (20 wt.\%) in diamond powder measured in the same conditions (not shown). In agreement with the literature (Janik, M. J.; Campbell, K. A.; Bardin, B. B.; Davis, R. J.; Neurock, M., Applied Catalysis A: General 2003, 256 (1-2), 51-68), the latter bands are positioned at 1080, 980, 885 and $790 \mathrm{~cm}^{-1}$, respectively. $\log (1 / \mathrm{R})$ is expressed in arbitrary units, with the reflectance $\mathrm{R}=\mathrm{I}_{\text {sample }} / \mathrm{IKBr}$. The weak bands at 1300 and $1405 \mathrm{~cm}^{-1}$ on spectra (b) and (c) are attributed to bidentate nitrate and nitrite species, respectively (Weng, X.; Dai, X.; Zeng, Q.; Liu, Y.; Wu, Z., Journal of Colloid and Interface Science 2016, 461, 9-14). 

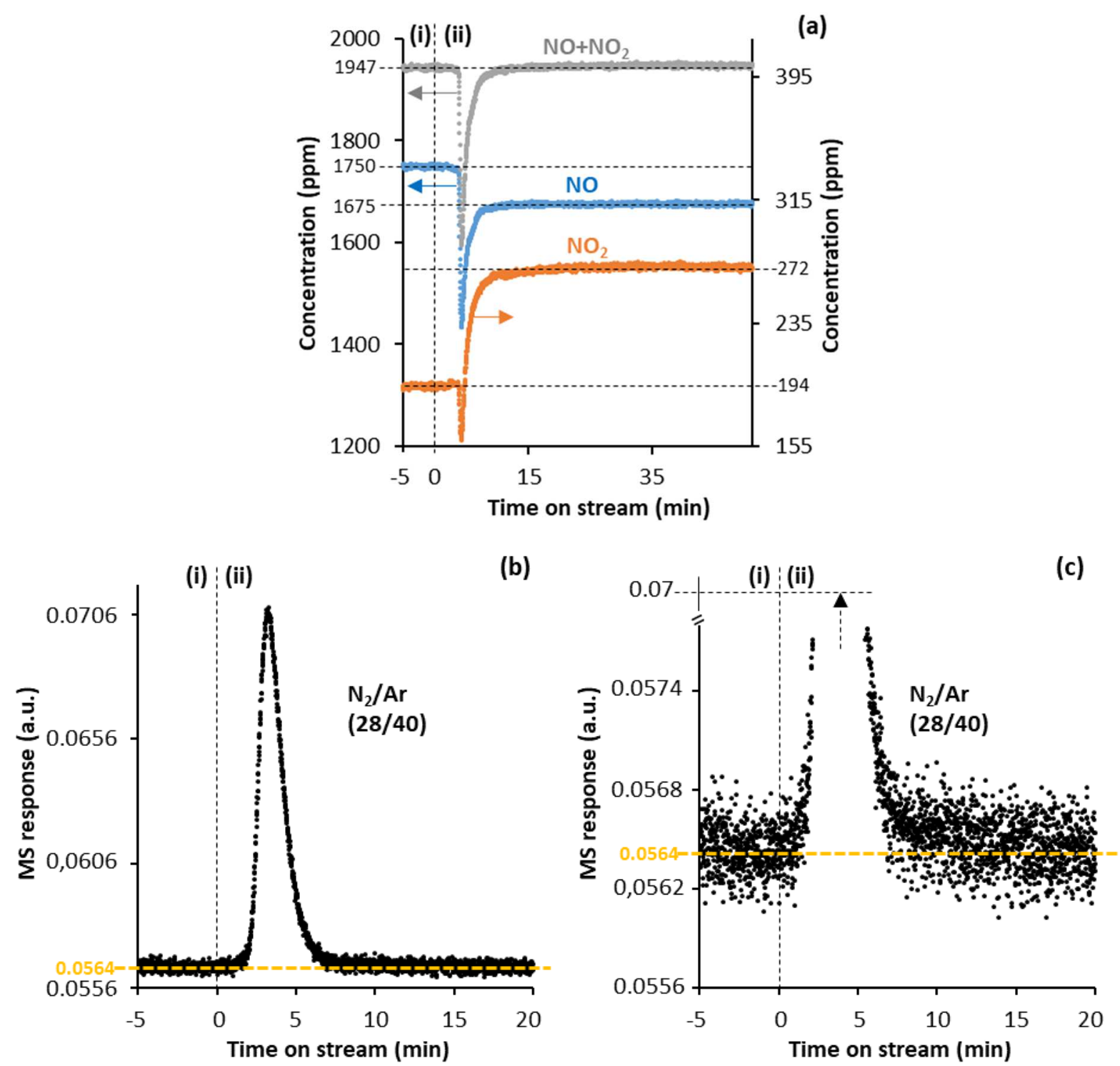

Figure S3. $\mathrm{NO}$ and $\mathrm{NO}_{2}$ concentrations recorded by the MKS MultiGas 2030 IR analyzer (a) and mass to charge (m/z) ratio 28 associated with $\mathrm{N}_{2}$ normalized by the m/z 40 one associated with Ar recorded by the MS (b-c) as a function of time on stream in the blank $\mathrm{NO}_{x}$ decomposition experiment with only quartz wool in the reactor (no catalyst) at $380{ }^{\circ} \mathrm{C}$ and a reaction feed of $\mathrm{NO}(\sim 2000 \mathrm{ppm})$ in $\mathrm{O}_{2}(5 \%)-\mathrm{Ar}(13 \%) / \mathrm{He}(50 \mathrm{mLNTP} / \mathrm{min})$. In (b) and (c), the same $\mathrm{N}_{2} / \mathrm{Ar}$ trace is shown with two different y axis scales. In (i), the reaction feed was analyzed without flowing through the reactor (upon flowing exclusively through lines at RT). In (ii), the reaction feed was flowing through the reactor at $380{ }^{\circ} \mathrm{C}$, and the outlet gas flow was analyzed over time-on-stream. In (a), the negative peaks centered at $10 \mathrm{~min}$ are attributed to the purge of the dead volume of the reactor upon introduction of the reaction feed. In (b) and (c), the $\mathrm{N}_{2} / \mathrm{Ar}$ peak centered at $8 \mathrm{~min}$ is attributed to the release of air from the dead volume of the reactor, and/or to the introduction of air trapped in the valve that was turned for contacting the reaction feed with the sample. In (c), the upper intensity of this peak was cut from the graph, as indicated by the rising arrow. 


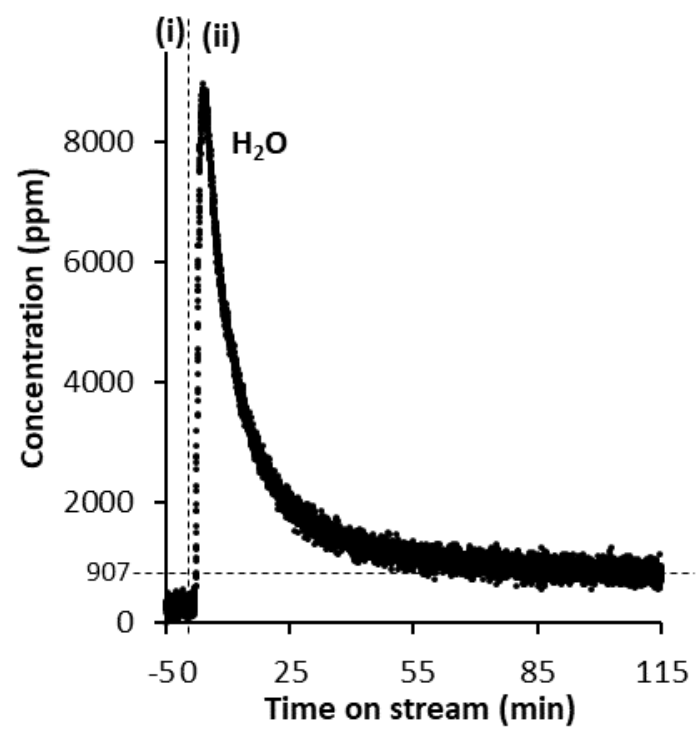

(a)

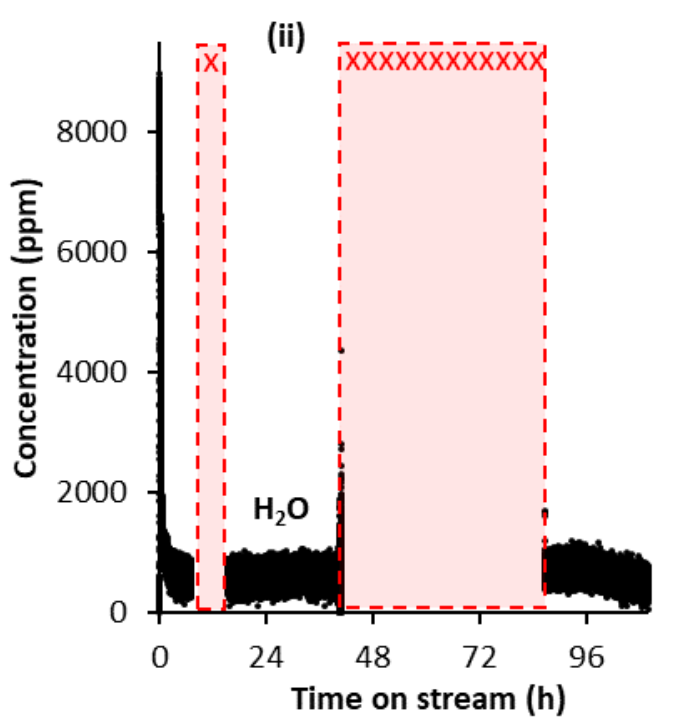

(b)

Figure S4. $\mathrm{H}_{2} \mathrm{O}$ concentration recorded by the MKS MultiGas 2030 IR analyzer as a function of time on stream in the preexposure of HPW12 $(2.5 \mathrm{~g},<125 \mu \mathrm{m})$ to a $50 \mathrm{mLNTP} / \mathrm{min}$ feed of $\mathrm{NO}(\sim 2000 \mathrm{ppm})$ in $\mathrm{O}_{2}(5 \%)-\mathrm{Ar}(13 \%) / \mathrm{He}$ at RT, to yield the P-HPW12 sample. In (i), the feed was analyzed without being contacted with the sample. In (ii), the feed was contacted with the sample, and the outlet gas flow was analyzed over time-on-stream. In (b), the same trace as in (a) is shown over a longer time scale. The periods marked with crosses $(\mathrm{xxx})$ correspond to night and/or weekend periods in which the cryo-detector of the IR analyzer could not be filled with liquid $\mathrm{N}_{2}$. 

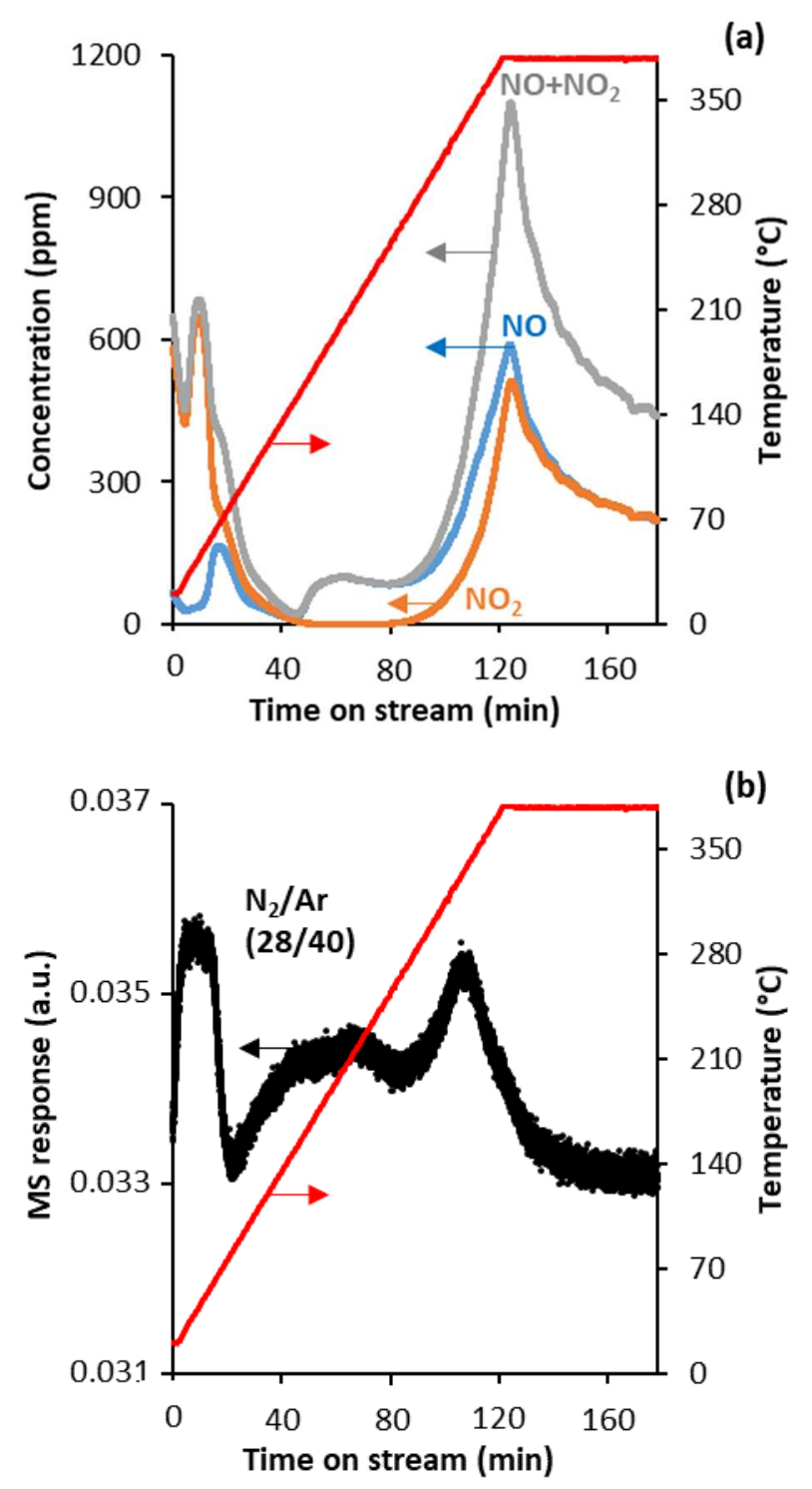

Figure S5. (a) $\mathrm{NO}$ and $\mathrm{NO}_{2}$ concentrations and temperature trace recorded by the MKS MultiGas 2030 IR analyzer as a function of time on stream upon heating P-HPW12 (prepared by the treatment monitored in Figures 2 and S4) from RT to $380{ }^{\circ} \mathrm{C}$ at 3 ${ }^{\circ} \mathrm{C} / \mathrm{min}$ under $\operatorname{Ar}(8 \%) / \mathrm{He}(50 \mathrm{mLNTP} / \mathrm{min})$. The areas under the $\mathrm{NO}$ and $\mathrm{NO}_{2}$ traces correspond to $7.42 \times 10^{-5} \mathrm{~mol}$ of $\mathrm{NO}$ and $7.61 \times 10^{-5} \mathrm{~mol}$ of $\mathrm{NO}_{2}$, respectively. (b) In the same experiment, temperature trace recorded by the MKS MultiGas 2030 IR analyzer and mass to charge $(\mathrm{m} / \mathrm{z})$ ratio 28 associated with $\mathrm{N}_{2}$ normalized by the $\mathrm{m} / \mathrm{z} 40$ one associated with Ar recorded by the MS. 


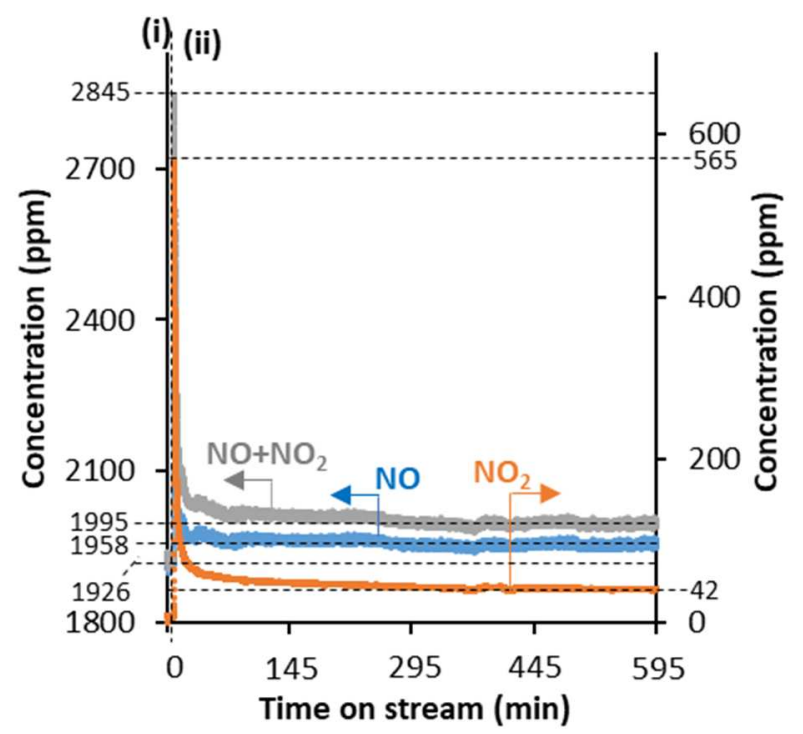

Figure S6. Same traces as those in Figure 4, but over a longer time scale - $\mathrm{NO}$ and $\mathrm{NO}_{2}$ concentrations recorded by the $\mathrm{MKS}$ MultiGas $2030 \mathrm{IR}$ analyzer $v s$. time on stream in the $\mathrm{NO}_{x}$ decomposition experiment with P-HPW12 $(2.5 \mathrm{~g},<125 \mu \mathrm{m})$ at 380 ${ }^{\circ} \mathrm{C}$ and a reaction feed consisting of $\mathrm{NO}(\sim 2000 \mathrm{ppm})$ in $\operatorname{Ar}(13 \%) / \mathrm{He}(50 \mathrm{~mL}$ NP/ $/ \mathrm{min})$. In (i), the reaction feed was analyzed without being contacted with the sample (upon flowing exclusively through lines at RT). In (ii), the reaction feed was continuously contacted with the sample at $380{ }^{\circ} \mathrm{C}$, and the outlet gas flow was analyzed over time on stream. P-HPW12 was heated from RT to $380{ }^{\circ} \mathrm{C}$ at $3{ }^{\circ} \mathrm{C} / \mathrm{min}$ under $\operatorname{Ar}(8 \%) / \mathrm{He}(50 \mathrm{mLNTP} / \mathrm{min})$.
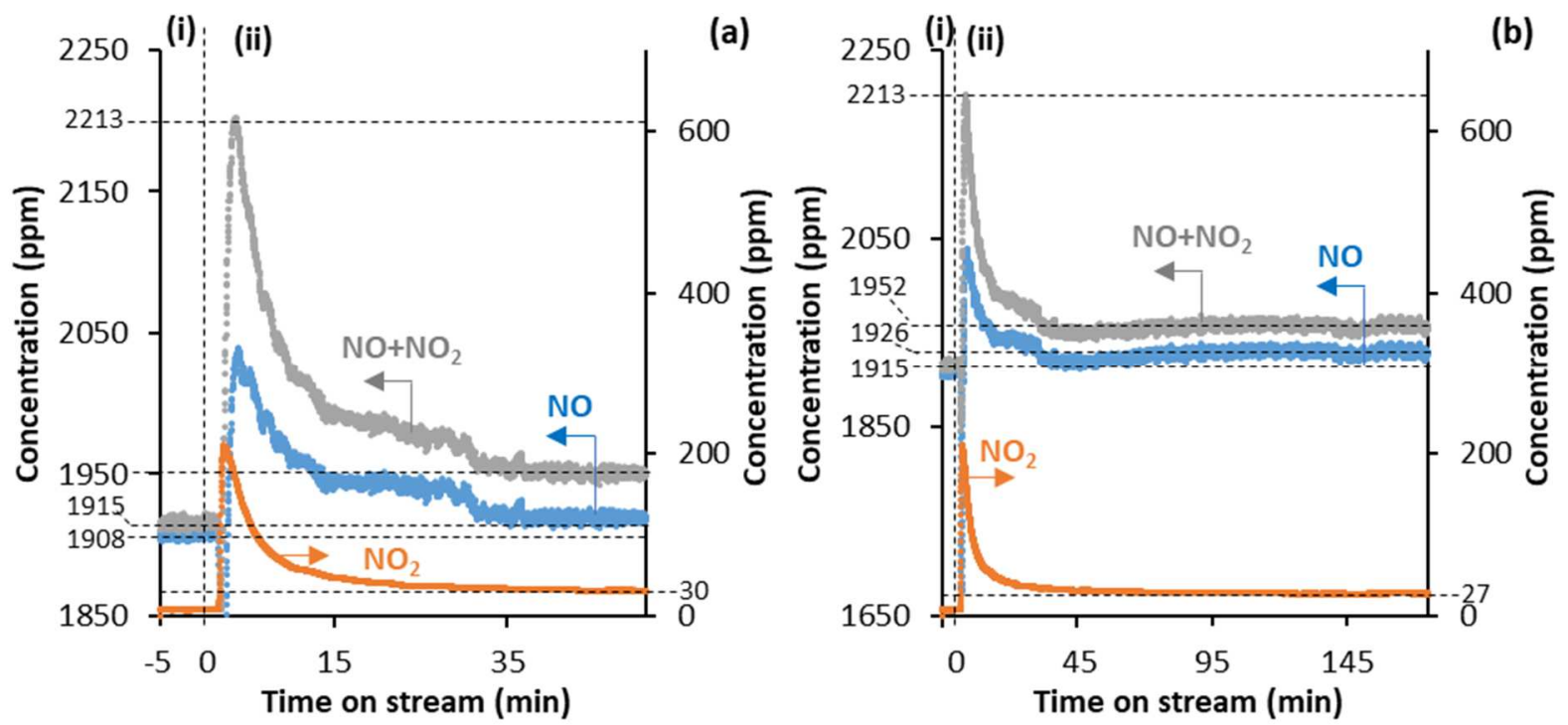

Figure S7. $\mathrm{NO}$ and $\mathrm{NO}_{2}$ concentrations recorded by the MKS MultiGas 2030 IR analyzer $v s$. time on stream in the second $\mathrm{NO}_{x}$ decomposition experiment with P-HPW12 $(2.5 \mathrm{~g},<125 \mu \mathrm{m})$ at $380{ }^{\circ} \mathrm{C}$ and a reaction feed consisting of NO $(\sim 2000 \mathrm{ppm})$ in $\operatorname{Ar}(13 \%) / \mathrm{He}(50 \mathrm{mLNTP} / \mathrm{min})$. In (i), the reaction feed was analyzed without being contacted with the sample (upon flowing exclusively through lines at RT). In (ii), the reaction feed was continuously contacted with the sample at $380{ }^{\circ} \mathrm{C}$, and the outlet gas flow was analyzed over time on stream. This experiment was launched after P-HPW12 had been purged for $10 \mathrm{~h}$ under He at $380{ }^{\circ} \mathrm{C}(50 \mathrm{mLNTP} / \mathrm{min})$ following the first $\mathrm{NO}_{x}$ decomposition experiment monitored in Figure $\mathrm{S} 6$. 

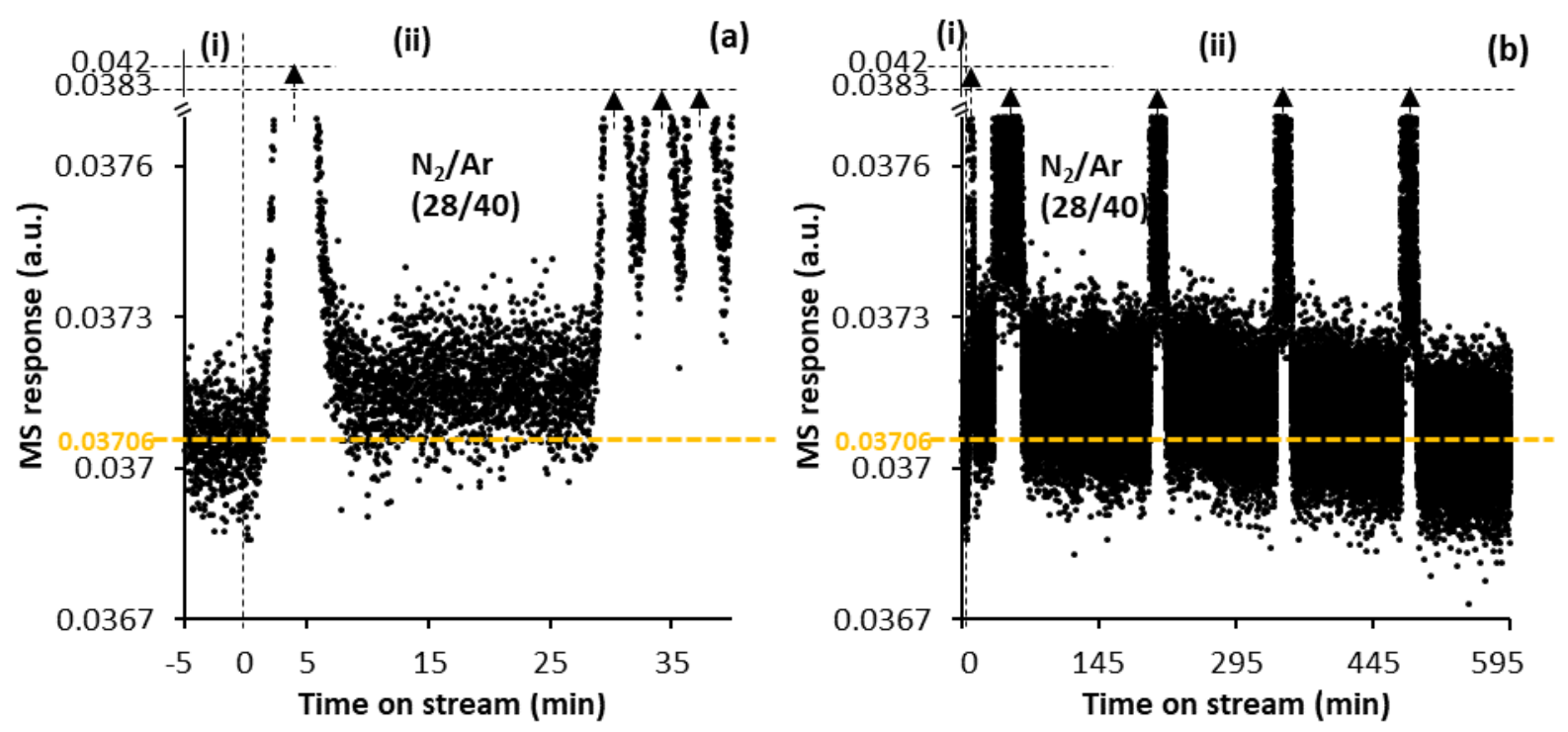

Figure S8. Same trace as that shown in Figure 5b, but over longer time scales, i.e. (a) 45 min and (b) 600 min. Mass to charge $(\mathrm{m} / \mathrm{z})$ ratio 28 associated with $\mathrm{N}_{2}$ normalized by the $\mathrm{m} / \mathrm{z} 40$ one associated with Ar recorded by the MS as a function of time on stream in the $\mathrm{NO}_{x}$ decomposition experiment with P-HPW12 $(2.5 \mathrm{~g},<125 \mu \mathrm{m})$ at $380{ }^{\circ} \mathrm{C}$ and a reaction feed of $\mathrm{NO}(\sim 2000$ $\mathrm{ppm})$ in $\mathrm{O}_{2}(5 \%)-\mathrm{Ar}(13 \%) / \mathrm{He}(50 \mathrm{mLNTP} / \mathrm{min})$. In (i), the reaction feed was analyzed without being contacted with the sample (upon flowing exclusively through lines at RT). In (ii), the reaction feed was continuously contacted with the sample at 380 ${ }^{\circ} \mathrm{C}$, and the outlet gas flow was analyzed over time-on-stream. P-HPW12 was heated from RT to $380{ }^{\circ} \mathrm{C}$ at $3{ }^{\circ} \mathrm{C} / \mathrm{min}$ under $\operatorname{Ar}(8 \%) / \mathrm{He}(50 \mathrm{mLNTP} / \mathrm{min})$. Except the first one attributed to the release of air trapped in the valve that served for contacting the reaction feed with the sample, the peaks marked with arrows are artifacts related to the simultaneously ongoing $\mu$-GC analysis.

1) NO

2) $\mathrm{NO}+\mathrm{O}_{2}$

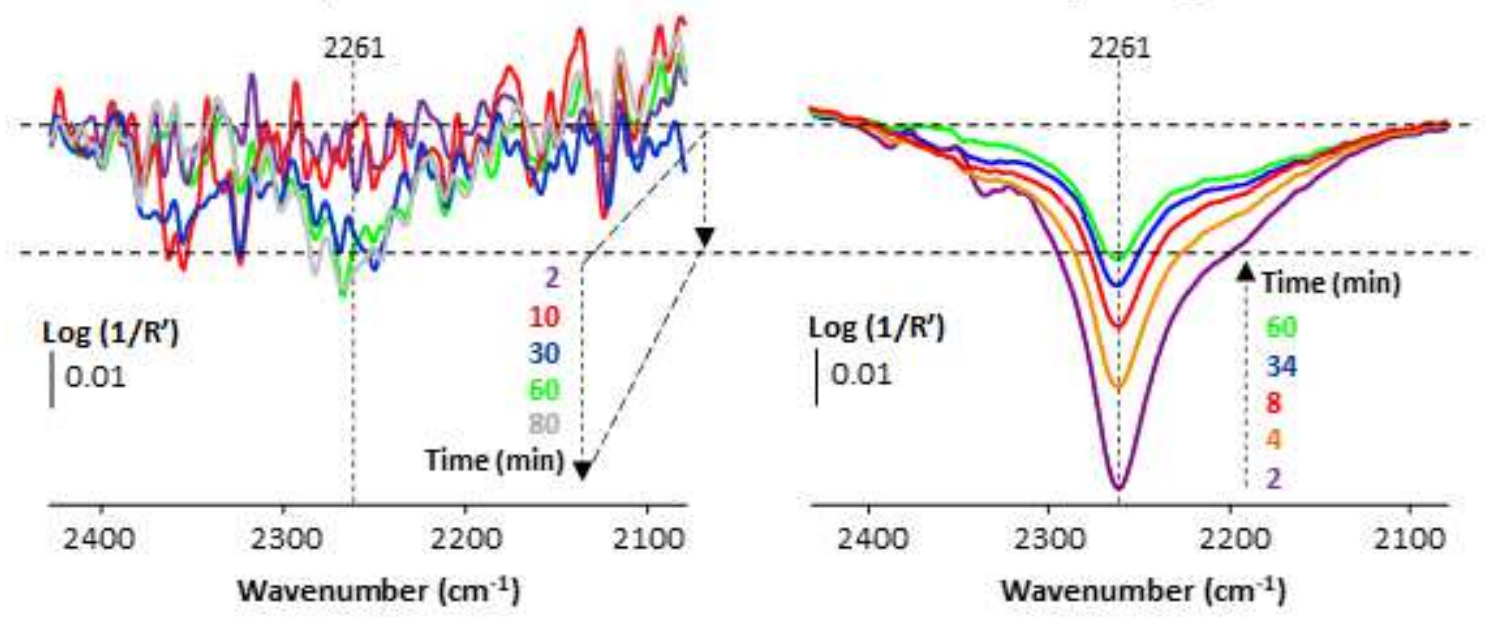

Figure S9. In situ DRIFT difference spectra of P-HPW12 at $380{ }^{\circ} \mathrm{C} v$ s. time of exposure to a feed of 1) NO ( 2000 ppm) in $\operatorname{Ar}(40 \%) / \mathrm{He}(50 \mathrm{mLNTP} / \mathrm{min})$ and subsequently 2) $\mathrm{NO}(\sim 2000 \mathrm{ppm})$ in $\mathrm{O}_{2}(5 \%)-\operatorname{Ar}(40 \%) / \mathrm{He}(50 \mathrm{mLNTP} / \mathrm{min})$, in the spectral region of $\mathrm{N}=\mathrm{O}$ stretches within $\mathrm{NOH}^{+}$and $\mathrm{HNO}_{2}{ }^{+}$species. P-HPW12 was heated from RT to $380{ }^{\circ} \mathrm{C}$ at $3{ }^{\circ} \mathrm{C} / \mathrm{min}$ under $\operatorname{Ar}(40 \%) / \mathrm{He}(50 \mathrm{~mL}$ NTP/min $)$. The difference spectra were obtained by subtraction of the last spectrum at $380{ }^{\circ} \mathrm{C}$ under $\operatorname{Ar}(40 \%) / \mathrm{He}$ measured before the reaction feed - $\mathrm{NO}$ without $\mathrm{O}_{2}$ in step 1 , vs. NO with $\mathrm{O}_{2}$ in step 2 - was contacted with the P-HPW12 sample. The low signal to noise ratio of the spectra recorded in the absence of $\mathrm{O}_{2}$ in the feed is attributed to the presence of water in the atmosphere of the spectrometer due to a reduced purge. $\log \left(1 / \mathrm{R}^{\prime}\right)$ is expressed in arbitrary units, with the relative reflectance $\mathrm{R}^{\prime}=\mathrm{I}_{\text {sample }} / \mathrm{I}_{\text {(reference sample) }}$. 
